\title{
Las políticas de cuidado de los niños a nivel nacional en España (1975-1996)
}

\section{C elia Valiente Fernández ${ }^{1}$}

U niversidad Autónoma de M adrid. D epartamento de Sociología.

28049 M adrid. Spain

E-mail: celia.valiente@uam.es

\section{Resumen}

D esde 1975 las principales políticas de cuidado de los niños deámbito nacional en España han consistido en la puesta en marcha de un alto número de programas educativos para niños de cuatro y cinco años, lo cual contrasta con la escasa oferta de tales servicios para los menores de tres años. Al examinar el papel desempeñado por distintos actores sociales y políticos en la fase del proceso de toma de decisiones políticas denominada el «establecimiento de la agenda» (agenda setting), podemos observar que los actores que desde 1975 podían haber demandado otro tipo de medidas (principalmente el movimiento de mujeres, las feministas de Estado y de los sindicatos) no las han reivindicado o lo han hecho tímidamente, debido a la influencia de los siguientes factores: el pasado político autoritario; las peculiaridades del mercado de trabajo; las características del Estado de bienestar, y las concepciones de amplios sectores de la población acerca del cuidado de los menores. En realidad, en este área de política pública se han desarrollado en las dos últimas décadas las medidas ya existentes antes de 1975, esto es, los servicios educativos en centros públicos para niños mayores de tres años.

Palabras clave: cuidado de los niños, España, establecimiento de la agenda, escuelas infantiles.

\begin{abstract}
T he Spanish child care policies (1975-1996)
A distinguishing feature characterizes the main Spanish central-state child care policies (for children under six, when mandatory education starts). M ost policies are educational pre-school programs for children aged three or over. The scope of these programs is quite high in comparative terms. In contrast, the percentage of Spanish children aged two or under cared for in public centers is one of the lowest in the European U nion. The characteristics of Spanish child care policy can be understood by examining the political agenda, and the role played
\end{abstract}

1. D esearía agradecer a Berta Álvarez-M iranda, M iguel Beltrán, M anuel Jiménez y Leonardo Sánchez sus valiosos comentarios a versiones anteriores de este trabajo, una de las cuales fue presentada en el XXXIth International Sociological Association Committee on Family Research Seminar on Children and Families: Research and Policy (Londres, 28-30 de abril de 1994) y forma parte del libro editado por Julia Brannen y M argaret O 'B rien Childhood and Parenthood. 
by the main social and political actors of the agenda setting stage. Those who might have emerged as determined advocates of more public child care programs after 1975, namely, the feminist movement, state feminists, and the women's departments of trade unions, have in practice not consistently advanced such demands. This paper examines why women's advocates either did not mobilize around child care issues, or were unable to introduce their demands into the government's agenda. The relevant explanatory factors include: the influence of the authoritarian political past; the characteristics of the labor market and the welfare state; and societal views on child rearing. Policy-makers have extended the programs which al ready existed before 1975, that is, educational services. They have been defined by policy-makers as measures that chiefly benefit children. Therefore, the policies are targeted at children aged three or over, because in Spain most policy-makers think that children should be enrolled in educational programs around the age of three.

Key words: child care, Spain, agenda-setting, pre-school services.

\begin{aligned} & \multicolumn{2}{c}{ Sumario } \\ & M arco teórico: el origen de Los actores sociales y políticos respecto \\ & las políticas públicas al cuidado de los niños \\ & Políticas públicas de cuidado Conclusión \\ & de los niños Bibliografía \end{aligned}

D esde 1975, las principales políticas de cuidado de los niños (hasta los seis años, edad en que comienza la escolarización obligatoria) de ámbito nacional en España se han caracterizado por dos rasgos distintivos, en comparación con otros países occidentales². En primer lugar, dichas políticas se han centrado en la puesta en marcha de un alto número de programas educativos para niños

2. En este artículo analizo las políticas que considero más importantes en función de dos criterios: el número de niños afectados y el volumen de recursos empleado para su financiación. Centro mi atención en dos tipos de medidas: por una parte, la oferta de programas para menores en centros públicos (en concreto, examino cuántos niños de cada grupo de edad acuden a un centro, y no otros aspectos, como la calidad de los programas o sus horarios) y, por otra, la regulación estatal de los centros privados y del sector de cuidados proporcionados en domicilios particulares a cambio de pagos en dinero, aś como las exenciones fiscales para los padres que incurran en gastos por cuidado de sus hijos. Pese a su interés, otras medidas no son estudiadas en este trabajo, por ejemplo, la provisión de atención médica, que habrán de ser objeto de una investigación posterior.

En cuanto a la terminología, no existe en castellano una expresión ya acuñada que haga referencia, de manera genérica, a las medidas que estudio. Utilizo entonces la de «políticas de cuidado de los niños», debido a que es la traducción literal de la que sí existe en inglés (childcare policies), y la utilizada en los informes de la O rganización para la Cooperación y el D esarrollo Económico (OCDE) sobre esta materia (OCDE, 1990). Esta expresión puede aplicarse también a los programas educativos, «ya que la escuela desempeña de facto el papel de "cuidador/a" durante las horas escolares» (O CDE, 1990: 305). Evito deliberadamente utilizar el vocablo "guardería», pese a que es un término bastante extendido en el lenguaje común, debido a que, para los profesionales del sector y las autoridades educativas, posee un matiz peyorativo. 
de cuatro y cinco años (en centros públicos gestionados por el M inisterio de Educación y Cultura, M EC, antes llamado deEducación y Ciencia), lo cual contrasta con la escasa oferta de tales servicios para niños menores de tres años. Así, en el año académico 1992-93, dos de cada tres niños de cuatro y cinco años de edad y uno de cada cuatro niños de tres años asistían a centros educativos públicos (que son gratuitos) $)^{3}$. En parte como resultado de ello, las tasas de escolarización (recogidas en la tabla 1) son notablemente altas en términos comparativos para niños de cuatro y cinco años (Boyd-Barrett, 1995: 10; M oss, 1990: 11; O CDE, 1990: 310), si bien las correspondientes a los menores de tres años son marcadamente bajas. En segundo lugar, la regulación estatal de las condiciones en que los centros privados ofertan servicios de cuidados a menores de seis años se ha llevado a cabo en España de forma más tardía y menos detallada que en otros países de nuestro entorno. Es más, el sector de cuidados proporcionados en domicilios particulares a cambio de pagos en dinero no está apenas reglamentado por las autoridades. España es, en este aspecto, diferente de otros países occidentales en los que el Estado ha intentado regular este último sector, si bien la puesta en práctica de esta reglamentación ha sido, en general, desigual y defectuosa.

En realidad, en el área de política de cuidado de los niños se han desarrollado notablemente durante los últimos veinte años las medidas ya existentes en España antes de 1975, esto es, los servicios educativos en centros públicos para niños mayores de tres años. Las autoridades educativas han definido estos programas como actuaciones cuyo principal fin es desarrollar en los niños determinadas habilidades y capacidades que les permiten aprender más y mejor una vez que inicien la escolarización obligatoria; los han destinado sobre todo a los de cuatro y cinco años, por entender que es en torno a los tres o cuatro años cuando los menores pueden (y deben) empezar a participar con regularidad y durante varias horas al día en actividades educativas. Las medidas nunca han sido entendidas como ayudas para que los padres (fundamentalmente las madres) compatibilicen sus responsabilidades profesionales y familiares. Si así hubieran sido concebidas (como políticas de igualdad de oportunidades de las mujeres), hubieran comprendido no sólo programas educativos para niños mayores de tres años, sino también servicios de cuidados para los más pequeños. Por otra parte, y puesto que en ningún país las jornadas escolares de los menores coinciden con las jornadas laborales de los adultos (en el caso de trabajos a tiempo total), ni siquiera durante el período escolar (E rgas, 1990: 200-201; O CDE, 1990: 309), los programas que nos ocupan también hubieran incluido, por

3. Las políticas educativas establecidas por el M EC afectaban en 1975 a todo el territorio nacional. En la actualidad lo hacen en el ámbito de gestión de este M inisterio (el llamado «territorio M EC»), esto es, en todas las comunidades autónomas salvo las siete que poseen competencias plenas en materia de educación (Andalucía, C anarias, C ataluña, G alicia, $\mathrm{N}$ avarra, País Vasco y C omunidad Valenciana). Las tasas de escolaridad de ámbito nacional en los años noventa son, entonces, el resultado de la política educativa del Gobierno central y de los gobiernos autonómicos con las mencionadas competencias. 
ejemplo, una oferta amplia de servicios complementarios en los centros públicos (de comedor y de actividades extraescolares), y una regulación de los centros privados y de los cuidados domiciliarios, a fin de potenciar este sector y elevar la calidad de su oferta.

En este artículo argumento que son varios los factores que explican por qué la igual dad de oportunidades de las mujeres no ha constituido el objetivo fundamental de las políticas de cuidado de los niños en España: 1) las peculiaridades del mercado de trabajo (el alto nivel de desempleo y la baja participación laboral de la mujer); 2) las características del Estado de bienestar (si se exceptúan la sanidad y la educación, las prestaciones más importantes son transferencias monetarias que mantienen un cierto nivel de renta para quienes ya no participan en el mercado de trabajo, existiendo muy pocos servicios sociales personales, por ejemplo, los de cuidados); 3) la opinión, compartida por amplios sectores de la población, de que los mejores cuidados que los niños menores de tres años pueden recibir son los proporcionados por sus madres en el hogar, y, por último, 4) el pasado político autoritario, que indirectamente ha desincentivado que algunos actores (el movimiento feminista y el feminismo institucional $)^{4}$ prestasen atención a la maternidad y asuntos afines (por ejemplo, la crianza de los hijos). El principal propósito de las políticas que nos ocupan ha consistido en la extensión de la educación en el nivel previo a la enseñanza obligatoria. Esta meta ha resultado relativamente poco controvertida, dado el bajo nivel de gasto público en educación antes de los años setenta, entre otros factores.

Si bien este trabajo se circunscribe a un único país, la experiencia española es analizada en comparación con la de otros, el egidos por existir acerca de ellos fuentes secundarias sobre las políticas de cuidado de los niños. Estos países (y las investigaciones que de ellos tratan) son Australia (Franway y otros, 1989), D inamarca (Borchorst, 1990), Estados U nidos (Gustafsson, 1994; Kahn y Kamerman, 1987), Francia (Jenson y Sineau, 1996), Gran Bretaña (Borchorst, 1990; Ruggie, 1984; Warner, 1994; W hittingham, 1994), N oruega (Leira, 1990), Suecia (D aune-R ichard y M ahon, 1996; G ustafsson, 1994; Ruggie, 1984) y los países escandinavos en general (Borchorst, 1990). H e utilizado, además, estudios comparativos sobre los países miembros de la O CDE (Ergas, 1990; OCDE, 1990) o de la Unión Europea (U E) (M oss, 1990).

En la primera parte de este artículo presento las premisas teóricas en que se basa el argumento explicativo, e identifico ciertas barreras que encuentran

4. Instituciones cuyo principal cometido es impulsar la formulación y puesta en práctica de medidas para al canzar un mayor grado de igualdad entre las mujeres y los hombres, se han fundado y consolidado en la mayor parte de los países occidentales desde aproximadamente los años setenta. En numerosas ocasiones, además, se han establecido organismos similares de considerable importancia en los ámbitos regional y/o local. En la literatura de ciencias sociales este conjunto de fenómenos se denomina «feminismo institucional», «feminismo de Estado» 0 «feminismo oficial» (Stetson y M azur, 1995). El «organismo de igual dad» más importante en España de ámbito nacional es el Instituto de la M ujer (Valiente Fernández, 1996). 
quienes intentan incluir entre las consideraciones de las élites políticas el objetivo de la igualdad de oportunidades para las mujeres (en el ámbito de la compatibilización de las responsabilidades profesionales y familiares). En la segunda describo sucintamente las características más destacadas de las principales políticas de cuidado de los niños en España desde 1975. En la última contrasto las proposiciones teóricas con un análisis de las posiciones y los comportamientos de los principales actores en este área de acción pública. La mayor parte de las fuentes aquí utilizadas son documentos publicados gubernamentales y de los partidos políticos, legislación, bibliografía y entrevistas personales a miembros de las asociaciones de mujeres, feministas de Estado, líderes de los departamentos de la mujer de las principales confederaciones sindicales y funcionarios del M EC y del M inisterio de Asuntos Sociales (M AS, desde 1996, M inisterio de Trabajo y Asuntos Sociales) ${ }^{5}$.

\section{M arco teórico: el origen de las políticas públicas}

En todas las sociedades son las mujeres quienes mayoritariamente proporcionan a sus hijos los cuidados que necesitan ${ }^{6}$, actividad que demanda considerables dosis de tiempo y esfuerzo. Las exigencias del papel de cuidadora no son necesariamente irreconciliables con las del trabajo extradoméstico, pero quienes intentan ser trabajadoras y madres simultáneamente se enfrentan al reto de hacer compatibles los requerimientos de su vida laboral y familiar. Toda política pública dirigida a facilitar esta compatibilización puede entenderse como una medida de igualdad de oportunidades para las mujeres, puesto que potencia su participación laboral ${ }^{7}$. En el caso español, sin embargo, en el área de actuación pública relativa al cuidado de los niños, el principal objetivo de las políticas públicas ha residido en ampliar las oportunidades educativas (en centros públicos) de los menores de seis años, pero no en promocionar el trabajo extradoméstico femenino. ¿Por qué ha sucedido así?

Para responder a esta pregunta resultan útiles al gunas aportaciones de los autores que analizan cómo se establece la agenda política (la lista de cuestiones a las que las élites gubernamentales prestan atención en un momento dado - Cobb y Elder, 1972: 14; Kingdom, 1984: 3). En primer lugar, en esta lite-

5. A fin de proteger el anonimato de las personas entrevistadas, y tal como acordé con ellas, sus nombres no aparecen en este trabajo.

6. Por ello, en este artículo me refiero a quienes actúan como principales cuidadores de sus hijos utilizando el femenino.

7. Estas políticas también se denominan de «igualdad de género». La literatura de ciencias sociales de orientación feminista habla de «géneros» en vez de «sexos» al denominar a los hombres y/o a las mujeres en su conjunto, por entender que la palabra «sexos» hace referencia principalmente a las diferencias físicas entre unos y otras, mientras que el vocablo «géneros» alude sobre todo a las diferencias de origen social, educativo, cultural y económico que entre ambos existen, y que, según dicha literatura, son las fundamentales (y no las de origen biológico). 
ratura se afirma que una política pública se instituye únicamente cuando los decisores políticos perciben una situación como un problema al que deben intentar dar una solución. En segundo lugar, se propone que en el ámbito político la manera en que se definen los problemas condiciona el modo de resolverlos (C obb y Elder, 1972: 30; D ery, 1984: 16-17; Kingdom, 1984: 207; N elson, 1984: 13, 23).

En su estudio sobre el establecimiento de la agenda del Gobierno Federal de Estados U nidos, John Kingdom (1984: 188-191) muestra que para que nuevos asuntos se incluyan entre los que ocupan la atención de los decisores políticos, es necesaria la actuación de lo que él denomina «promotores» 0 «valedores de políticas» (policy entrepreneurs). Los define como individuos que intentan que preval ezcan sus concepciones respecto a cuáles son los problemas que el Gobierno debe tratar y/o acerca de cuáles son las mejores soluciones para resolverlos. Caracteriza a estos «valedores» su disposición a invertir en tal empeño ciertos recursos (tiempo, energía, reputación y dinero). D efienden sus propuestas a cambio de recibir beneficios de diverso tipo, tales como la aprobación final de las medidas que propusieron y apoyaron, la satifisacción derivada de participar en el proceso de toma de decisiones políticas, o la obtención de un ascenso profesional. Estos «valedores» se encuentran tanto dentro como fuera del sistema político concebido en sentido estricto, y son o pueden ser muchos tipos de personas: políticos, funcionarios, miembros de grupos de presión, consultores, académicos, etc. En otros lugares también se ha señalado la importancia de los «promotores» (bien actores individuales o colectivos), a fin de que nuevos asuntos terminen formando parte de la agenda gubernamental (C obb y Elder, 1972: 13; N elson, 1984: 122).

Si bien la mayoría de los autores realiza estudios de casos en los que la agenda política cambia al incluir «nuevas» cuestiones (Kingdom, 1984; N elson, 1984, entre otros) ${ }^{8}$, todos insisten en la dificultad que entraña modificar dicha agenda, debido a razones distintas. En primer lugar, y por obvio que resulte, un número muy elevado de asuntos forma parte de la misma de modo permanente. Ello obliga a los políticos a decidir sobre muchos problemas en la nada envidiable situación de escasez de tiempo y de recursos, y a mostrarse notablemente renuentes ante la perspectiva de tener que ocuparse de materias adicionales. En segundo lugar, los «val edores» de nuevas cuestiones pueden no contar con los suficientes recursos para influir con eficacia en el sector adecuado de la arena política, a fin de convencer a las élites gubernamentales para que examinen «su» problema e intenten darle «su» solución. Por último, es posible que no aparezcan «promotores» de un nuevo asunto, ni dentro ni fuera del sistema político (C obb y Elder, 1972: 10, 89; Kingdom, 1984: 213).

¿Cuáles son los factores que explican que en al gunos casos nadie actúe como «val edor» de una política pública determinada? La opinión de amplios sectores de la población es importante en este sentido; en general, los decisores polí- 
ticos no intentarán enfrentarse a determinados problemas, si buena parte de los cuidadanos opina que no es prerrogativa de los poderes públicos (sino de la sociedad) el hacerlo (Cobb y Elder, 1972: 86; N elson, 1984: 4-5). D esde otra perspectiva, se han apuntado razones relativas a las características de los nuevos asuntos en cuestión. Así, éstos podrán entrar en la agenda política si su planteamiento y solución son congruentes con la situación económica del país y/o con la capacidad institucional de un Estado para ejecutarlos. En segundo lugar, la formulación del problema ha de llevar asociada una o varias soluciones posibles dado que los políticos, a diferencia posiblemente de los académiCOS, no suelen dedicar tiempo al planteamiento de cuestiones que no pueden resolver. Por último, la materia ha de poder ser planificada en términos no controvertidos, a fin de que en torno a ella se genere un consenso acerca de la oportunidad de la intervención estatal y de la solución proporcionada (consenso que posiblemente se traducirá en cotas más altas de aceptación de la gestión del Gobierno por parte de los cuidadanos) (Bachrach y Baratz, 1962: 950; 1963: 632; Kingdom, 1984: 93, 210; N elson, 1984: 27-29).

En cada área posible de actuación pública, el número de problemas que los decisores políticos pueden plantear e intentar resolver es muy el evado. Por ejemplo, en materia medioambiental un G obierno puede mostrar preocupación ante lo que considera un tibio compromiso de la población con el mantenimiento del entorno físico, un al to grado contaminante de las actividades productivas, o un escaso número de estudios científicos de calidad sobre el caso. D ependiendo de cuál de los tres subproblemas decida resolver, este $G$ obierno realizará una campaña de sensibilización de la opinión pública acerca de la gravedad del deterioro del mundo natural, prohibirá determinadas actividades económicas, o subvencionará uno o varios estudios en profundidad sobre la degradación del ecosistema. Cabe imaginar que los «valedores» de estas tres subcuestiones competirán entre sí para que en la esfera política termine prestándose atención a «su» problema y poniendose en marcha «su» solución. A estas aportaciones de la literatura añado la afirmación de que la competición dentro de una misma área temática es clave para entender el proceso político porque, en ocasiones, el esfuerzo realizado por los gobernantes respecto a uno de los subasuntos implica que no presten atención a los otros; ello sucederá si, por ejemplo, declina posteriormente el interés gubernamental por la cuestión en conjunto, o la actuación de los gobernantes les conduce a pensar que la intervención estatal en la materia medioambiental es, por el momento, suficiente. En otras palabras, la existencia de una política pública en determina do campo dificulta o impide, a veces, que los decisores políticos formulen medidas acerca de otros asuntos próximos.

Por otra parte, es importante destacar que, si bien algunas de las obras «clásicas» sobre el establecimiento de la agenda gubernamental son trabajos fundamental mente teóricos (Bachrach y Baratz, 1962; 1963), la mayoría examina, además, casos empíricos de procesos de toma de decisiones políticas en regímenes democráticos (C obb y Elder, 1972; Crenson, 1971; Kingdom, 1984; N elson, 1984; Schattschneider, 1975 [1960]). N o obstante, al analizar un caso 
como el español, cabe plantear si la existencia de un régimen autoritario previo influye en el proceso de formación de la agenda de los futuros gobernantes democráticos. La respuesta es afirmativa, por cuanto nuevos actores políticos y sociales (algunos de ellos inexistentes o prohibidos en el pasado) plantean nuevas demandas, al gunas de las cuales son consideradas por los gobernantes del período posautoritario.

0 tras dimensiones de la influencia del pasado autoritario en la configuración de la agenda política resultan menos evidentes. En este sentido, son clarificadoras las hipótesis de N ancy Bermeo (1992: 274-281), quien defiende que las experiencias vividas durante un período autoritario pueden contribuir a que los decisores políticos y los actores sociales rechacen al gunas prácticas y comportamientos fácilmente asociables con el autoritarismo. En esta línea, acuña el concepto de «aprendizaje político» (political learning), definiéndolo como «el proceso por el cual las personas modifican sus creencias y tácticas políticas como resultado de graves crisis, frustraciones y cambios dramáticos en el entorno». Añade que «el aprendizaje político consiste en el proceso de "desacreditar" antiguas creencias». Basándome en estas proposiciones de N ancy Bermeo, argumento que la experiencia autoritaria impide en ocasiones que ciertos actores democráticos se conviertan en «valedores» de una política pública determinada, por ejemplo, si las cuestiones a que se refiere pudieran ser vistas como las preferidas por las élites políticas no democráticas. Si ello fuera cierto, en otros contextos nacionales sin un pasado autoritario, dichos actores probablemente habrían actuado como los «promotores» de la mencionada política.

En las páginas siguientes analizo el caso empírico de las medidas relacionadas con el cuidado de los niños en España en los últimos veinte años. En primer lugar describo los principales programas en este ámbito de actuación pública. A continuación, con ayuda de las aportaciones de la literatura sobre el establecimiento de la agenda política, explico por qué en España se han puesto en práctica sobre todo programas en centros educativos públicos, y no otro tipo de medidas. Examino con especial atención dos cuestiones: si en el ámbito de los servicios para los niños la ejecución de al gunos programas ha inhibido la aparición de otros, y si el pasado autoritario ha impedido la movilización de ciertos actores demandando una política más intensiva.

\section{Políticas públicas de cuidado de los niños}

En esta sección describo concisamente las principales medidas de ámbito nacional relativas al cuidado de los niños menores de seis años en España: la provisión de plazas en centros públicos, las actuaciones dirigidas a los centros privados (las subvenciones que reciben, las becas públicas de las que se benefician sus alumnos y la regulación estatal de las condiciones en que estos centros ofertan sus servicios), la ausencia de reglamentación estatal del sector de cuidados que se proporcionan en los domicilios particulares y, en último lugar, la concesión de exenciones fiscales a al gunos padres en concepto de gastos por el cuidado de sus hijos. 
Tabla 1. Tasas netas de escolarización* de niños de 0 a 5 años totales, por edad y tipo de centro, curso 1992-1993. Fuente: cálculos propios a partir de datos contenidos en INE (1994: 27, 1995: 5) y M EC (1995: 91).

\begin{tabular}{lrcc}
\hline Edad & Total & Centros públicos & Centros privados \\
\hline 0 años & 0,6 & 0,3 & 0,3 \\
1 año & 2,8 & 1,3 & 1,5 \\
2 años & 8,7 & 3,0 & 5,7 \\
3 años & 46,0 & 24,3 & 21,7 \\
4 años & 97,1 & 66,1 & 31,0 \\
5 años & 100,0 & 67,7 & 33,1 \\
\hline
\end{tabular}

* La tasa neta de escolaridad es la relación entre el alumnado de una edad concreta de la enseñanza considerada respecto a la población de esa edad. (M EC, 1995: 18)

\section{Los centros públicos}

La provisión de plazas para mayores de tres años en centros educativos públicos es, con diferencia, la política más importante relacionada con el cuidado de los niños, tanto por el número de menores beneficiarios de ella, como por el volumen de recursos empleado para financiarla. La Ley 14/1970 de 4 de agosto (Ley G eneral deEducación, LGE) incluyó, por primera vez, a los niños de dos a seis años en el sistema educativo. Esta etapa, denominada «educación preescolar», se definió como no obligatoria y estaba dividida en dos ciclos: el jardín de infancia, para niños de dos y tres años, y la escuela de párvulos, para los de cuatro y cinco años 9 . Por su parte, la Ley O rgánica 1/1990 de 3 de octubre (Ley de O rdenación G eneral del Sistema Educativo, LO GSE), vigente en la actualidad, establece que el sistema educativo comprende el período 0-6 años de edad. Esta etapa educativa mantiene su carácter voluntario, y se divide en dos ciclos: el primero, hasta los 3 años de edad, y el segundo, de los tres a los seis años (CECS, 1994: 380).

La proporción de niños de cuatro y cinco años que en España asiste a centros educativos públicos (que son gratuitos hoy día) ha venido aumentando desde 1975. En efecto, si en el curso 1975-1976 uno de cada cuatro niños de cuatro y cinco años (25\%) era alumno de un centro de este tipo ${ }^{10}$, en el de 1992-1993 lo eran ya dos de cada tres (66\% y 68\%), según puede observarse en la tabla 1. El porcentaje equivalente de niños de tres años se ha incrementado, si bien no ha alcanzado niveles tan altos, ya que ha pasado del $4 \%$ en

9. El sistema educativo anterior a la LGE, cuyas bases fueron sentadas por la Ley de Instrucción Pública de 9 de septiembre de 1987, conocida como «Ley M oyano», comprendía tres niveles: la primera enseñanza, para niños de seis a nueve años, la segunda enseñanza, de seis años de duración, y la superior (D e Puelles Benítez, 1986: 144-146; M cN air, 1984: 18).

10. H e calculado este porcentaje a partir de los datos contenidos en IN E (1977: 101; 1981: 12). 
Tabla 2. Alumnado matriculado en enseñanza anterior a la obligatoria por edad y tipo de centro, España, cursos 1975-76 y 1992-93.

\begin{tabular}{lrlll}
\hline Curso & \multicolumn{1}{c}{ Total } & Centros públicos & Centros privados & $\begin{array}{l}\text { \% de alumnos en } \\
\text { centros públicos }\end{array}$ \\
\hline $1975-76$ & 920.336 & 347.026 & 573.310 & $38 \%$ \\
$1992-93$ & 1.052 .488 & 670.455 & 382.033 & $64 \%$ \\
\hline
\end{tabular}

Fuente: MEC (1989b: 37; 1995: 91).

1987-1988 al 24\% en 1992-199311. En otras palabras, en los últimos veinte años las autoridades educativas han expandido notablemente la cobertura de las medidas que ya existían con anterioridad, esto es, los programas educativos para niños sobre todo de cuatro y cinco años; lo mismo cabe afirmar, en la década de los noventa, de los servicios educativos para los de tres años.

En parte como resultado de dicha política, las tasas de escolarización en centros públicos para niños de cuatro y cinco años son, en la actualidad, elevadas en términos comparativos, lo que no puede afirmarse para los de tres años (C onsejo Escolar del Estado, 1995: 136). Por otra parte, esta creciente oferta de plazas educativas para niños de tres a seis años en centros públicos explica que, si bien en el curso 1975-1976 el 38\% de los niños menores de seis años que acudía a un centro lo hacía a uno público, en 1992-1993 el porcentaje equivalente era el $64 \%$, según puede observarse en la tabla 2 . Visto desde otra perspectiva, a mediados de los años setenta, el sector público ofertaba algo más de una de cada tres de las plazas para menores que aún no habían iniciado la escolarización obligatoria, mientras que en la actualidad oferta dos de cada tres de ellas.

El número de plazas en centros públicos para menores de tres años es sumamente reducido. EI M EC no gestiona centros con clases para estos niños, dejando la provisión de estos servicios en manos de otras administraciones públicas, por ejemplo, las corporaciones locales, y de entidades privadas sin fines de lucro. Pese a que el artículo 11.2 de la LO G SE afirma que el M EC debe establecer convenios con todas las instituciones y organizaciones citadas, sólo se ha firmado un número muy reducido de estos convenios (Consejo Escolar del Estado, 1995: 137; D oz O rrit, 1995: 84). Por lo que se refiere al M inisterio de Asuntos Sociales (M AS, desde 1996 M inisterio de Trabajo y Asuntos Sociales), éste ha llevado a cabo algunas políticas relacionadas con el cuidado de los niños, si bien de mínima importancia en comparación con las del M EC. EI M AS, creado en 1988, no administra centros educativos, pero desde 1991 subvencionaba proyectos organizados por los ayuntamientos (las comunidades autónomas habían de cofinanciarlos). El fin de algunos de estos proyectos

11. Estos porcentajes han sido calculados a partir de datos provenientes de IN E (1994: 27; 1995: 5) y M EC (1991: 40, 64; 1995: 91). 
residía en ofertar plazas en centros, además de otros servicios, a niños de cero a tres años de edad. EI M AS intentaba que de estas y otras medidas se beneficiaran menores cuyas familias se encontraran en situaciones particularmente desfavorecidas (CECS, 1994: 380-381; Consejo Escolar del Estado, 1995: 102-104; Fernández Sanz, 1990: 9, 17).

\section{Los centros privados}

En lo que concierne a los centros privados, el número de los que reciben subvenciones del M EC por el hecho de ofertar plazas a niños menores de seis años ha sido tradicional mente muy reducido $0^{12}$, si bien esta dimensión de la política educativa está cambiando en 1996, con la llegada al poder del Partido Popular, cuyos líderes políticos han manifestado explícitamente su propósito de incrementar estas subvenciones (EI País, 4 de agosto de 1996: domingo 3; 8 de octubre de 1996: 27). Es preciso resaltar que en los últimos años las autoridades educativas han venido subvencionando preponderantemente centros privados que ofertan plazas en los niveles de escolarización obligatoria (educación primaria y educación general básica). Pocos son también los centros privados que ofertan plazas a niños de cero a seis años que han recibido subvenciones del M AS (CECS, 1994: 381-382)13. Por último, el M EC tiene a su cargo un programa de becas para familias con niños de tres a seis años que asisten a centros privados, si la familia solicita esta ayuda y si el nivel de ingresos familiares no supera cierto umbrall4.

La regulación de las condiciones en que los centros privados ofertan sus servicios apenas existía, en la práctica, hasta la aprobación de la LO GSE y, en la actualidad, aún no afecta a la mayoría de los centros. D esde 1990, las condiciones mínimas que han de caracterizar a los centros educativos públicos (por ejemplo, en términos de número de niños por cuidador, o de espacio físico por cada niño) también deben aplicarse a los privados de nueva creación ${ }^{15}$. Los centros privados establecidos antes de 1990 disponen de un plazo de diez años (hasta el 2000) para adecuarse a estos requerimientos mínimos, no siendo aún mayoría los que ya lo han hecho. Algunos centros privados ofertan ser-

12. Por ejemplo, en 1993/1994, en el territorio M EC, 796 centros privados (3.089 unidades) impartían el segundo ciclo de educación infantil (3-6 años) de acuerdo con los criterios establecidos por la LO GSE. D e ellos, 23 centros (55 unidades), esto es, un 3\% de los centros o un $2 \%$ de las unidades, estaban subvencionados (C onsejo Escolar del Estado, 1995: 338-339).

13. En este sentido, desde 1989 el M AS ha subvencionado organizaciones no gubernamentales sin ánimo de lucro que gestionaban proyectos dirigidos a niños menores de seis años, algunos de los cuales eran escuelas infantiles (Fernández Sanz, 1990: 8-9).

14. D urante el curso 1993-94 el número de niños que en el territorio nacional recibió estas becas fue de 39.397; la cuantía media de las becas ascendió a 44.845 pesetas (Consejo Escolar del Estado, 1995: 270-280).

15. Estas condiciones mínimas quedaron fijadas por el Real D ecreto 1.004/1991 de 14 de junio. 
vicios de calidad excelente, si bien muchos otros habrían de cerrar sus puertas si fueran obligados a adaptarse inmediatamente a las condiciones mínimas (D oz O rrit, 1995: 84). En suma, si comparamos la experiencia española con la de otros países desarrollados (W hittingham, 1994), en el nuestro la reglamentación estatal de este sector está teniendo lugar de manera más laxa y en un momento más tardío (CECS, 1994: 381).

\section{El sector domiciliario}

Por lo que se refiereal sector domiciliario, apenas está en España regulado por el Estado, a diferencia de otros países, como Estados Unidos (Kahn y Kamerman, 1987: 203-42), Francia (Jenson y Sineau, 1996: 11-12) o Gran Bretaña (Warner, 1994), si bien es éste un ámbito en el que la práctica suele escapar, en buena medida, a la regulación por parte de las autoridades (O CDE, 1990: 303). N o está reglamentada, por ejemplo, la cualificación que los cuidadores han de poseer, ni el número máximo de niños por cuidador, ni las condiciones físicas de la vivienda. En España, las disposiciones legislativas que afectan a estos cuidadores son las relativas al servicio doméstico, las cuales definen la condición laboral de los empleados de hogar como trabajadores, esto es, fijan aspectos tales como el salario, el horario de trabajo, las vacaciones 0 las cotizaciones a la Seguridad Social. Al igual que en otros países, en España el servicio doméstico opera en buena medida en el sector sumergido de la economía, por lo que estas reglamentaciones se incumplen en un número significativo de los casos.

\section{Las exenciones fiscales}

Por último, desde 1991, los contribuyentes del I mpuesto sobre la Renta de las Personas Físicas (IRPF) pueden beneficiarse de una deducción de la cuota del $15 \%$ de los «gastos de custodia de hijos» menores de tres años (hasta un máximo de 25.000 pesetas anuales). Los rendimientos netos del sujeto pasivo no han de superar los 2 millones de pesetas anuales ( 3 millones en caso de tributación conjunta) y ambos padres han de trabajar fuera del domicilio familiar. En el ejercicio fiscal de 1994 (correspondiente a la renta generada en 1993), 106.299 contribuyentes se vieron afectados por esta deducción de la cuota, cuyo valor medio ascendió a 11.835 pesetas (M EH , 1995: 108). Exenciones fiscales de este tipo también se aplican en otros países de la UE, como Portugal, Francia, Bélgica o Luxemburgo (M oss, 1990: 10), o en Estados U nidos, donde constituyen desde los años ochenta la medida más importante de ámbito fede ral dirigida a ayudar a las familias a sufragar los gastos derivados del cuidado de los niños (Ergas, 1990: 204-205; G ustafsson, 1994: 56-57; Kahn y Kamerman, 1987: 21; OCDE, 1990: 335-336).

En síntesis, en las dos últimas décadas, la política relacionada con el cuidado de los niños más importante en España (en términos de menores afectados y de recursos utilizados para financiarla) ha consistido en la expansión 
de las medidas que ya existían, esto es, de los programas educativos en centros públicos para niños sobre todo de cuatro y cinco años de edad. Como resultado de ello, el porcentaje de menores que acude a estos centros en dichas edades es elevado en términos comparativos. Puesto que el sector privado también oferta un número no despreciable de plazas, la tasa de escolarización de estos niños en ambos tipos de centros es también destacable. Por el contrario, otras medidas se han desarrollado bastante menos (la provisión de plazas en centros públicos para niños menores de tres años, la subvención de centros privados que ofertan plazas en el nivel anterior a la escolarización obligatoria, la concesión de becas a alumnos que asisten a estos últimos, la regulación de las condiciones en que los centros privados prestan sus servicios, o las exenciones fiscales), mientras que la reglamentación estatal del sector de cuidados domiciliarios no ha tenido lugar. En el siguiente epígrafe exploro algunos de los factores que explican por qué ha sido ésta y no otra la política de cuidado de niños en España tras 1975.

\section{Los actores sociales y políticos respecto al cuidado de los niños}

Como explico en las páginas siguientes, el caso de las políticas de cuidado de los niños en la España democrática puede entenderse como una cuestión de agenda política. En otros países, ciertos actores (principalmente los grupos feministas, las feministas de Estado y los departamentos de la mujer de las principales confederaciones sindicales) han actuado como «promotores» de una amplia oferta de servicios de cuidado para los niños pequeños, a fin de facilitar a sus madres la compatibilización de sus responsabilidades familiares y laborales. En España estos tres actores no se han comportado de tal modo, en parte por razones relativas al pasado político autoritario. En este área de actuación pública, los «valedores» de política han sido entonces las autoridades educativas, quienes han hecho prevalecer su definición acerca de cuáles eran las cuestiones más acuciantes de este sector a las que el Estado debía proporcionar una respuesta. En líneas generales, han mantenido que el mayor problema radicaba en una oferta insuficiente de programas educativos, en especial de aquéllos en los que pudieran participar niños procedentes de familias poco privilegiadas social, económica y culturalmente. Esta definición del problema ha traído aparejada una solución: el aumento del número de plazas en centros públicos, esto es, el desarrollo de los programas que para niños menores de seis años ya existían con anterioridad a 1975. Esta extensión de los programas educativos ha resultado ser una política poco controvertida, dadas la aceptación social de estos programas por parte de amplios sectores de la población, y sus concepciones acerca de que la mejor manera de cuidar a los niños menores de tres o cuatro años es en el ámbito familiar. Esta política ha sido congruente con el funcionamiento del mercado de trabajo español (en el que existe una gran escasez de puestos de trabajo) y con las características del Estado de bienestar (que ofrece pocos servicios sociales personales, entre ellos los de cuidados). 
A continuación examino las posiciones de distintos actores en el área de la política del cuidado de los niños. Trato, en primer lugar, de los que han permanecido en buena medida inactivos en este ámbito (el movimiento feminista, el feminismo institucional y los departamentos de la mujer de las principales confederaciones sindicales). Analizo después la posición de los distintos partidos políticos en el tema que nos ocupa, para finalizar con un examen de la gestión de las autoridades educativas.

El movimiento feminista, el feminismo institucional y los departamentos de la mujer de las confederaciones sindicales

En cuanto al movimiento feminista en España durante los últimos veinte años ${ }^{16}$, no ha incluido un incremento de la oferta pública de servicios de cuidados de los niños en su lista de reivindicaciones más urgentes, si bien su retórica sí ha enfatizado la importancia de esta reivindicación. Es preciso destacar que, en este sentido, España no ha sido tan peculiar, puesto que algo similar ha sucedido en algunos países, por ejemplo los nórdicos o Gran Bretaña (Borchorst, 1990: 174-75), si bien no en otros, como Francia (Stetson, 1987: 139). Es más, en muchos países, los servicios creados y gestionados por las feministas para ser utilizados por ellas mismas o por otras mujeres han consistido, normalmente, en gabinetes de planificación familiar, despachos de asesoramiento jurídico (por ejemplo, para casos de separación o divorcio), así como refugios para mujeres mal tratadas y otros servicios dirigidos a víctimas de la violencia. Los centros de cuidados para niños, sin embargo, casi nunca han sido establecidos por las militantes de este movimiento (Franzway y otros, 1989: 65).

Por otra parte, el bagaje teórico de muchas feministas ayuda a explicar por qué no incluyeron una más amplia oferta pública de servicios de cuidado de los niños en la lista de demandas prioritarias. Las militantes españolas han realizado muy pocas aportaciones a la teoría feminista internacional, y han adquirido la mayor parte de sus premisas teóricas leyendo traducciones de al gunas obras escritas por autoras de otros países (Threlfall, 1985: 59-60). En general, a principios de los años setenta, la maternidad era ignorada por los escritos feministas internacionales, con la subsiguiente indiferencia hacia todo lo relacionado con el cuidado de los niños. M ás adelante, a mediados de esa déca da, dicha literatura reflejó un interés creciente por la maternidad, no obstante lo cual, contenía únicamente referencias bastantes confusas acerca de las necesidades de los niños, y pocas y vagas propuestas sobre cómo organizar en la vida diaria su cuidado (Franzway y otros, 1989: 61). Las feministas españolas, influenciadas por estas teorías internacionales (y por otras posteriores muy similares), no han considerado (ni siquiera en nuestros días) el cuidado de los menores como un asunto de gran importancia, sobre el que mereciera la pena reflexionar y debatir en profundidad. Esta indiferencia teórica se ha traduci-

16. Los párrafos dedicados al movimiento feminista están basados en Scanlon (1990), Threlfall (1985) y siete entrevistas en profundidad realizadas para Valiente Fernández (1996). 
do en inacción en términos políticos. Así, en la práctica, y pese a la consigna del movimiento de «lo personal es político», la cuestión del cuidado de los hijos se ha terminado considerando un asunto privado que, llegado el momento, cada mujer (o cada pareja) había de resolver por sí misma.

Si bien las afirmaciones contenidas en párrafos anteriores podrían aplicarse en cierta medida al movimiento feminista de muchos países de nuestro entorno, un factor histórico específico, el régimen político autoritario de derechas, contribuye a explicar por qué las feministas españolas no han actuado como «promotoras» de una amplia política de cuidado de los niños. En primer lugar, es importante tener presente que la existencia del período franquista significó que, desde 1975, el movimiento feminista en España ha debido perseguir un número más elevado de objetivos que en otros países, donde al gunos de ellos ya se habían al canzado. Estas metas consistían, entre otras, en la equidad de derechos políticos para los ciudadanos de ambos sexos, la igualdad de hombres y mujeres ante la ley, las reformas en el área de los dere chos reproductivos (tales como la despenalización de la comercialización y publicidad de los anticonceptivos o la legalización del aborto), una ley del divorcio y el castigo de la violencia sexual. En este contexto, la mejor estrategia ha consistido en proponer únicamente al gunas demandas, sobre todo si se tiene en cuenta que el movimiento de mujeres en España, en comparación con el de otros países de nuestro entorno, es más débil por lo que se refiere a su número de militantes y simpatizantes, su grado de visibilidad en los medios de comunicación, y su capacidad para iniciar debates públicos de gran audiencia.

En segundo lugar, al no luchar por obtener una mayor oferta de servicios para niños, las feministas estaban rechazando en España, en mayor medida que en otros países, un pasado sumamente problemático. La doctrina oficial del régimen franquista definía la maternidad como la principal aportación de las mujeres a su país y su sociedad, además de afirmar que esta actividad era incompatible con otras, por ejemplo, el trabajo extradoméstico (N ash, 1991: 160). Como en tantas otras cuestiones, el discurso del régimen autoritario fue matizándose en sus últimos años, pero nunca dio en esta materia un giro radical. Es preciso destacar que fue en los años setenta cuando se fundaron muchos grupos feministas, y que junto con otras organizaciones políticas (ilegales) participaron en la oposición al régimen franquista (Scanlon, 1990: 94). Lo último que resultaba atractivo para estas militantes después de 1975 era prestar atención a la maternidad y cuestiones afines. La tarea pendiente de la liberación de las mujeres fue entendida entonces de manera dual: en términos de un aumento de su participación en determinadas efferas, tales como el mercado de trabajo o el poder político, además de como una consecución de derechos individuales, por ejemplo, el del control de la capacidad reproductiva. Esta definición eludía cuidadosamente el lugar de la maternidad y del cuidado de otras personas en las vidas de las nuevas mujeres emancipadas. En cuanto al feminismo oficial, organismos de igualdad han existido en España desde la segunda década de los años setenta. La principal institución 
de este tipo de ámbito nacional es el Instituto de la $M$ ujer (IM ), creado en 1983, por lo que analizo su posición en el área de políticas de cuidado de los niños ${ }^{15}$.

En otros países, por ejemplo, Australia, desde las instituciones feministas se ha ejercido presión sobre las autoridades, a fin de que las mencionadas políticas fueran más generosas (Franzway y otros, 1989: 59-60). No ha sucedido lo mismo en España, donde plantear esta reivindicación no ha formado nunca parte de las prioridades del IM ${ }^{18}$.

Las feministas de Estado en España han ignorado el asunto del cuidado de los niños por las mismas razones que lo han hecho las activistas del movimiento de mujeres: el elevado número de demandas que habían de avanzar; su preparación teórica (que les ha llevado a prestar poca o ninguna atención a la maternidad y a cuestiones con ella relacionadas); y el intento de distanciarse lo más posible de los temas que pudieran asociarse con el pasado político no democrático.

Posiblemente haya influido también en esta posición de indiferencia ante el problema colectivo del cuidado de los niños la situación laboral de buena parte (aunque no de la totalidad) de las feministas institucionales. La labor de compatibilización de las responsabilidades familiares y profesionales es, sin duda, ardua para la mayoría de las mujeres que realizan trabajo extradoméstico. Sin embargo, en comparación con el resto de las mujeres, las feministas de Estado gozan de un estatus profesional que les ayuda a simultanear con mejor fortuna ambas obligaciones. Ello es así debido a que perciben un salario algo más elevado (que en algunos casos les permite contratar servicio doméstico) y trabajan en el sector público, donde, en líneas generales y con importantes excepciones, algunos derechos de los trabajadores (por ejemplo, las bajas de maternidad/paternidad, las excedencias por cuidado de hijos, o la hora de ausencia del trabajo por lactancia de un hijo menor de nueve meses) se respetan en la práctica más que en el sector privado. Un argumento similar (aunque con matices) podría elaborarse con respecto a las militantes del movimiento feminista, ya que la mayor parte de ellas pertenece en España, al igual que en muchos otros países, a la clase media, por lo que cuenta con más recursos que las mujeres de extracción social más baja a la hora de resolver, a título individual, el problema del cuidado de sus hijos.

17. Los dos documentos programáticos más importantes del IM son los planes para la igualdad de oportunidades de las mujeres (IM , 1987, 1993b), los cuales, junto con las memorias de actividades del IM (IM , 1986, 1988; 1989; 1990b; 1991; 1992; 1993a; 1994), y diecisiete entrevistas en profundidad realizadas en el organismo de igualdad para otro trabajo (Valiente Fernández, 1996), constituyen las principales fuentes para la redacción de este epígrafe.

18. U no de los principales cometidos del IM reside en impulsar políticas de igualdad de oportunidades. Es importante entender que en la mayor parte de los casos el IM no formula ni pone en práctica por sí mismo dichas medidas, puesto que no tiene competencias ni recursos suficientes para ello. N ormalmente, el I M presiona a otras instituciones para que establezcan políticas de igualdad. 
Por lo que se refiere a los departamentos de la mujer de las principales confederaciones sindicales (U GT y C CO O), sus miembros han expresado públicamente su preocupación ante las dificultades que encuentran muchas mujeres para cumplir con los requerimientos derivados del trabajo extradoméstico y de la crianza de sus hijos. Asimismo, han destacado que parte del problema reside en la escasez de servicios públicos de cuidado de niños de calidad y de coste asequible, y han instado (sobre el papel, véase infra) a las autoridades a que expandan la oferta existente ${ }^{19}$. No resulta sorprendente que estas feministas sindicales (a diferencia del feminismo oficial o de las militantes del movimiento) hayan abordado estos asuntos, puesto que están, por lo general, más en contacto (y de una manera más directa) con el común de las trabajadoras y sus problemas.

No obstante lo anterior, en general, estos departamentos sindicales en la práctica tampoco han presionado activamente y de manera eficaz a las élites políticas en el ámbito nacional para que extendieran las medidas ya existentes sobre el cuidado de los niños, o establecieran otras nuevas. Tampoco han incluido reivindicaciones en esta dirección al participar en la negociación colectiva, por ejemplo, solicitando la creación de centros de cuidados para niños adjuntos a las empresas donde las madres (o los padres) trabajan, o la implantación de ayudas monetarias como complemento del salario de los progenitores que incurren en gastos por la custodia de niños.

Son dos los factores que explican esta disonancia entre el ideario de estos departamentos y sus modos de proceder: por una parte, al igual que en el caso de las militantes del movimiento de mujeres y de las feministas de Estado, el alto número de tareas pendientes; por otra, la poca importancia relativa de estos departamentos dentro de las confederaciones sindicales. Esta posición de debilidad se refleja, entre otros aspectos, en el bajo número de personas empleadas en ellos o en su escasa capacidad de incluir en el discurso y las prácticas de toda la confederación sindical cualquier asunto relativo a la desigualdad entre los trabajadores de ambos sexos. Tanto es así que, incluso si todas las sindicalistas feministas hubieran estado de acuerdo en la importancia de la cuestión del cuidado de los niños, y hubieran aunado fuerzas en la demanda de medidas más generosas en este ámbito (lo que no ha sucedido), hubieran tenido que negociar, en primer lugar, no con los empresarios o con las élites políticas, sino con los propios sindicalistas.

Permítaseme ilustrar esta última afirmación haciendo referencia a la negociación colectiva. Para la mayor parte de los líderes sindicales, los asuntos más importantes en la negociación con los empleadores han sido y son, sobre todo, los incrementos salariales, la reducción de los horarios y la estabilidad en el empleo (Pérez D íaz y Rodríguez, 1994). Las cuestiones relativas a la equiparación

19. Ello se desprende de las fuentes primarias escritas consultadas (Secretaría C onfederal de la M ujer de C CO O , 1993a; 1993b) y de las entrevistas a dos líderes del D epartamento de la M ujer de U GT realizadas para este trabajo. 
de los trabajadores de ambos sexos, por ejemplo las ayudas que los empleadores pudieran conceder a los asalariados en materia de cuidado de sus hijos, ni siquiera se mencionan cuando se prepara y negocia un convenio. M uy pocas veces, generalmente en el caso de que alguna sindicalista feminista participe en el proceso, se incluye al guna referencia a tales temas, asegurándose el resto de los representantes sindicales que será una de las primeras reivindicaciones que se abandonen, a fin de obtener logros en las materias consideradas prioritarias $^{20}$. En este sentido, España contrasta con otros países, por ejemplo, Suecia, donde las principales confederaciones sindical es han impulsado, junto con las élites políticas, una extensa oferta pública de servicios de cuidados para niños (D aune-Richard y M ahon, 1996: 12-17).

En suma, en general, ni las asociaciones de mujeres, ni el feminismo institucional, ni los departamentos de la mujer de las confederaciones sindicales han actuado, en la práctica, como «valedores» de una amplia política de servicios de cuidado de los niños. Por otra parte, la literatura sobre el establecimiento de la agenda insiste en que es más probable que un asunto sea incluido en la lista de cuestiones a las que las élites gubernamentales prestan atención cuando amplios sectores de la población creen que el Estado debe intervenir en la materia, y cuando las posibles soluciones al problema son congruentes con la situación económica del país o con la capacidad institucional del Estado para enfrentarse a este tipo de cuestión. A continuación explico que, en el caso español hubiera sido dificultoso para cualquier actor plantear la demanda de una oferta más amplia de servicios públicos de cuidados para niños (entendidos como medidas que facilitan que sus madres compatibilicen sus obligaciones profesionales y familiares), dadas las características del Estado de bienestar (que oferta pocos servicios sociales), la situación del mercado de trabajo (donde existe un exceso de oferta de mano de obra) y las opiniones de muchas personas acerca de la mejor forma de cuidar a los niños pequeños (los cuidados maternos proporcionados en el hogar).

Por lo que respecta al Estado de bienestar, desde sus orígenes ha sido un sistema contributivo y profesional, esto es, financiado predominantemente con las cotizaciones de los trabajadores y sus empleadores. Salvo la sanidad y la educación (dos excepciones muy importantes), la mayor parte de sus prestaciones son transferencias monetarias para mantener un cierto nivel de renta de aquéllos que, habiendo participado en el mercado de trabajo (y contribuido a la financiación del sistema), ya no lo hacen por diversas circunstancias (paro involuntario, jubilación, enfermedad o invalidez, principalmente). En términos comparativos, muy pocos beneficios consisten en servicios sociales

20. La indiferencia de las confederaciones sindicales hacia las políticas de cuidado de los niños se refleja, por ejemplo, en el silencio de la mayoría de los documentos sindicales ante estas cuestiones. H e consultado las resoluciones de los congresos confederales de CC O $O$ y U G T celebrados en la última década, y he encontrado muy pocas referencias a este tipo de medidas (CCO O , 1984; 1988; 1991; UGT, 1986; 1990; 1994). 
personales, entre los que se encuentran los de cuidados (Esping-Andersen, 1990; 1995; G uillén, 1992; 1996) ${ }^{21}$.

En cuanto a la situación del mercado de trabajo, cabe destacar que en países como Suecia a finales de los años sesenta y principios de los setenta (Gustafsson, 1994: 51; Ruggie, 1984; D aune-Richard y M ahon, 1996: 10), D inamarca (Borchorst, 1990: 172) o N oruega (Leira, 1990: 140-143), la escasez de trabajadores, junto con otros factores, se encuentran (en distinto grado) en el origen de una extensión de la provisión pública de servicios de cuidados para niños, a fin de facilitar el empleo de las mujeres casadas con hijos. Éstas constituían la reserva más importante de mano de obra, una vez que se hubo excluido el empleo de un alto número de trabajadores inmigrantes. Esta falta de trabajadores disponibles ha sido absolutamente desconocida en España en los últimos veinte años.

En la actualidad, la tasa de actividad femenina en España (35\%) es, junto con la de G recia y después de la de Italia (34\%), la segunda más baja de toda la UE, situándose diez puntos por debajo de la media europea (45\%). La tasa de ocupación femenina es en España (25\%) la más baja en la UE, a catorce puntos de distancia del valor medio europeo (39\%). Es más, la tasa de paro femenino en nuestro país (30\%) no sólo es la más alta de toda la Unión, sino que asciende prácticamente el doble de la siguiente más alta (16\%, correspondiente a Italia y Finlandia) y a más del doble de la media de la UE (12\%) (Eurostat, 1996: 8-9; datos de 1995)22. Ello significa, de un lado, que el mercado de trabajo en España no proporciona a las autoridades ningún incentivo para que pongan en práctica medidas que contribuyan a incrementar la participación laboral de la mujer, al no demandar más trabajadores. D e otro lado, y a diferencia de lo que sucede en otros países, la baja tasa de ocupación femenina se traduce en que un número elevado de mujeres está dispuesto a trabajar como empleadas de hogar, realizando las tareas domésticas y cuidando los niños de familias de clase social superior a la suya. Esta baja tasa implica, además, que muchas mujeres que no realizan trabajo extradoméstico pueden ofrecerse para cuidar a los niños de otras mujeres de su familia (normalmente más jóvenes que ellas).

21. Según Esping-Andersen (1995: 2), en el Estado de bienestar de España y de algunos otros países (Italia, Francia, Alemania O ccidental, Austria, Bélgica y Portugal), a principios de los años noventa aproximadamente la décima parte de los recursos se dedicaba a servicios sociales (excluidos los servicios sanitarios), mientras que este porcentaje ascendía a un tercio en el de los países nórdicos.

Si se excluyen los servicios sanitarios, los servicios sociales incluyen, entre otros programas, los relativos al cuidado (en centros) de los niños, ancianos y minusválidos, servicios dirigidos a la juventud y cuidados domiciliarios, pero también prestaciones relacionadas con el empleo, por ejemplo, programas de rehabilitación.

22. La tasa de actividad es la proporción entre la población activa y la población total en edad de trabajar. La tasa de ocupación es la proporción entre la población ocupada y la población total en edad de trabajar. La tasa de paro es la proporción entre el número de parados y el de activos (ocupados más parados). 
Por lo que se refiere a las concepciones de la población acerca de cuál es el mejor tipo de crianza de los niños muy pequeños, existe evidencia que documenta la amplia aceptación de dos creencias, cuya veracidad es desmentida por numerosas investigaciones (M arsiglio, 1995: 7): en primer lugar, que los cuidados maternos resultan indispensables para los niños, al menos durante sus primeros años de vida; en segundo lugar, que las mujeres poseen un instinto natural del que carecen los hombres para proveer tales cuidados. D e ambas creencias se deriva la opinión de que los padres (o los trabajadores especializados en cuidar a menores), pueden ayudar en la crianza de los niños, pero en absoluto compartirla en pie de igualdad con sus madres (Aguinaga Roustán y Comas Arnau, 1991: 33; D e Pablo M asa, 1976: 377-382; Escario y otros, 1987: 84-88; I glesias de U ssel, 1984: 8-10; IN N ER, 1988: 54).

Visto lo anterior, no resulta difícil entender que muchas personas en España opinen que el trabajo extradoméstico de las madres es perjudicial para sus hijos (D e Pablo M asa, 1976: 375-376; Escario y otros, 1987: 55; IN N ER, 1987: 54; Juste 0 rtega y otros, 1991: 38-39). Por ejemplo, en una encuesta llevada a cabo en 1990, más de la mitad de la población española adulta de ambos sexos (55\%) declaraba estar de acuerdo con la proposición de que es probable que los niños menores de seis años sufran si sus madres trabajan fuera de casa. Cuando la pregunta se refería no ya a los menores de seis años sino a los hijos de cualquier edad, el nivel de aceptación del trabajo de la mujer aumentaba, ya queel $61 \%$ asentía ante la afirmación de que «a madre que trabaja puede tener una relación tan cálida y segura con sus hijos como una que no trabaja» (Alberdi y otros, 1994: 98-101).

Es en este contexto en el que debe entenderse la profunda desconfianza de muchos españoles hacia los centros donde se cuida a los niños, los cuales constituyen, para una considerable proporción de padres y madres, una de las opciones menos preferidas para sus hijos, sobre todo si no han cumplido los dos o tres años. El cuidado maternal es, según una inmensa mayoría de individuos, la mejor solución. Si la madre no permanece día y noche en el hogar a cargo de sus hijos, la segunda mejor opción para un buen número de españoles (a bastante distancia de la primera) resulta ser la más parecida a la presencia a tiempo completo de una madre ama de casa: bien el empleo de otra mujer, normalmente de clase social inferior, que sustituye a aquélla (para las parejas suficientemente acomodadas que pueden pagar dichos servicios); bien que los niños españoles sean cuidados por las abuelas y, en menor proporción, por otros, parientes femeninos (Aguinaga Roustán y Comas Arnau, 1991: 33, 35, 170-172; D e M iguel, 1994: 820; Escario y otros, 1987: 89-94; Juste O rtega y otros 1991: 43-44; Tobío, 1996: 93-95). Aquéllas se encuentran frecuentemente disponibles para encargarse de sus nietos, ya que muchas son amas de casa y viven cerca de sus hijos (D e M iguel, 1994: 804-805).

Las ideas acerca de la importancia de los cuidados maternos y de los dones naturales de las mujeres para proporcionárselos a sus hijos (de las que se deriva la opinión de que el trabajo extradoméstico de la madre es perjudicial para éstos), junto con la profunda desconfianza hacia los servicios ofertados por 
centros infantiles, no son privativas de España, sino que existen en otros países (Gerson, 1988: 121-124), aunque están más extendidas en el nuestro. Constituyen una barrera casi imposible de franquear para cual quier actor que intentara incluir la demanda de más servicios de cuidados infantiles en la agenda política gubernamental.

\section{Los partidos políticos}

La mayoría de los líderes políticos y de los altos cargos de libre designación son miembros de los partidos políticos que forman el Gobierno (y el grueso de la oposición), o se encuentran próximos a éstos. Por otra parte, los partidos son importantes vehículos de formación de la agenda política, puesto que recogen en sus programas electorales (a veces con mucha ambigüedad) cuestiones que son importantes para ciertos sectores de la población (C obb y Elder, 1972: 91), y a los que tal vez se dedicarán atención una vez en el Ejecutivo, 0 ejerciendo la oposición. Por estas dos razones, analizo en las páginas siguientes los programas de los partidos que han constituido el Gobierno y/o la principal fuerza de la oposición en las últimas dos décadas: U nión de Centro D emocrático (UCD ), el Partido Popular (PP, previamente bajo los nombres de Alianza Popular, Coalición D emocrática y Coalición Popular - AP, CD , CP) y el Partido Socialista O brero Español (PSOE). Presto especial atención a este último, por haber formado G obierno durante cuatro legislaturas. En general, en los programas de todas las formaciones políticas aparece la propuesta de incrementar la oferta educativa para los menores de seis años, mientras que, con excepciones, está ausente la de aumentar los servicios de cuidado de niños, con el fin de incentivar la participación laboral de sus madres.

Por lo que se refiere a U CD, el programa electoral de 1977 no contenía ninguna referencia a las cuestiones que nos ocupan. El de 1979 afirmaba, en la sección de educación, que la correspondiente al nivel preescolar (y de carácter gratuito) había de extenderse a todos los de cuatro y cinco años (UCD, 1979: 35). Si bien estos objetivos programáticos no se pusieron en práctica en toda su extensión en el período en el que este partido gobernó, merece ser destacado el hecho de que, ya a finales de la década de los setenta, las medidas dirigidas a los menores de seis años se entendían desde esta formación política como una extensión de los programas educativos existentes.

En cuanto al PSOE, el tratamiento de las medidas de cuidado de los niños realizado en sus programas electorales y en las resoluciones de sus congresos federales es algo más complicado que en el caso de U CD. En la sección de educación ambos tipos de documentos contienen compromisos de desarrollar programas educativos para menores de seis años. Las experiencias educativas previas a la escolarización obligatoria se entienden en estas fuentes como herra mientas para disminuir las desigual dades entre las clases sociales. D e acuerdo con estas premisas, si las plazas en los centros públicos fueran ocupadas por niños procedentes de familias desfavorecidas en términos económicos, sociales y culturales, estos programas educativos les proporcionarían una preparación 
suficiente para iniciar en buenas condiciones la etapa educativa obligatoria, además de servir para limar las diferencias entre estos menores y los provenientes de familias con más recursos. Las fuentes del PSO E aquí examinadas reflejan, en este sentido, la confianza depositada por los líderes y las bases de esta formación política en el sistema educativo como mecanismo capaz de reducir las desigualdades sociales (PSO E, 1979a: política sectorial 90, política municipal 8; 1981: 91, 277-279; 1982: 23-24; 1984: 66; 1986: 61, 63; 1988: 44; 1989: 29-30; 1990: 109; 1993: 29; 1996: 51-53).

Los documentos del PSOE contienen también, aunque en menor número, referencias a los servicios de cuidado de los niños en las secciones de igualdad de oportunidades para las mujeres (PSO E, 1976: 19; 1979a: política sectorial 19-20; 1979b: 22; 1981: 233; 1982: 29; 1989: 66; 1990: 61, 109; 1993: 59; 1996: 66-67). A primera vista, estas referencias Ilaman la atención, si se piensa que en este partido, al igual que en los socialdemócratas de otros países, los dirigentes y los militantes de base se han preocupado tradicionalmente más por la desigualdad entre las clases sociales que por la existente entre los hombres y las mujeres. Estas menciones han resultado de las presiones de las feministas socialistas, quienes paulatinamente habían venido ganando estatus organizativo dentro del partido ${ }^{23}$. Consiguieron introducir en los textos programáticos compromisos acerca de la extensión de los servicios de cuidados para los niños, entendidos éstos como medidas que favorecían la igualdad de los individuos de ambos sexos.

La inclusión de una declaración de intenciones en el programa electoral de un partido, sin embargo, no significa que vaya a llevarse a la práctica automáticamente, en caso de acceder al G obierno. D e hecho, las feministas socialistas apenas presionaron con posterioridad para que los compromisos citados se cumplieran, de modo que los correspondientes a los menores de tres años han resultado ser sobre todo retóricos.

La disposición de las feministas del PSO E a insistir en que los textos programáticos del partido incluyeran menciones al problema del cuidado de los niños (como a cualquier asunto que pudiera relacionarse de manera directa 0 indirecta con la igualdad de oportunidades de las mujeres), sin preocuparse posteriormente de que al gunas de estas referencias se convirtieran en políticas sustantivas, reflejaba la ambival encia de las militantes feministas del PSO E con respecto a los asuntos de la maternidad y del cuidado de los niños. Esta actitud era compartida con las activistas del movimiento de mujeres y con las feministas de Estado.

23. Así, en 1976 formaron el colectivo «M ujer y Socialismo». En un principio era poco más que un círculo de estudio y de debate dependiente de la Secretaría de Formación. En 1981 uno de sus miembros, Carmen M estre, fue el egida vocal de la Comisión Ejecutiva Federal del partido, y otras la siguieron en años posteriores. Finalmente, en diciembre de 1984, lograron que «M ujer y Socialismo» se convirtiera en una Secretaría Ejecutiva de la Comisión Ejecutiva Federal (T hrelfall, 1985: 48-49). Alusiones a la política de cuidado de los niños aparecen en Bustelo (1980: 1-2, 14, 17-19), PSO E/M ujer y Socialismo (1980) y PSO E/Secretaría de Formación (1977: 11), entre otros. 
Una de las líderes de la Secretaría Ejecutiva del PSOE mencionada en la nota anterior, M atilde Fernández Sanz, quien también había dirigido anteriormente el departamento de la mujer de U GT, fue nombrada M inistra de Asuntos Sociales en 1988, cuando se cré el M inisterio. Uno de los propósitos del mismo consistía en desarrollar políticas dirigidas a ciudadanos en situaciones especialmente desfavorables, como los inmigrantes o los minusválidos. $\mathrm{N}$ o resulta sorprendente que el M AS apenas desempeñara un papel activo en el área de los servicios de cuidados para los menores, como sí lo han hecho ministerios similares en otros países, por ejemplo, Francia (O CDE, 1990: 340) o Gran Bretaña (Warner, 1994: 27).

Respecto al PP, sus programas electorales han venido proponiendo una extensión de los servicios educativos anteriores a la etapa obligatoria ya existentes, incluyéndose estos compromisos programáticos en el epígrafe de política educativa (PP, 1977: 31; 1979: 45; 1982: 104-105; 1986: 9; 1989: 10; 1993: 56-58; 1996: 98-99) y, en mucha menor medida, en los relativos a la igualdad de oportunidades para las mujeres (PP, 1993: 81; 1996: 187-189) 0 al apoyo a la familia (PP, 1979: 37; 1982: 135; 1989: 29; 1996: 181-182).

\section{Las autori dades educativas ${ }^{24}$}

Según he explicado con anterioridad, la principal política pública de nivel nacional en el ámbito que nos ocupa ha sido la extensión de los programas educativos ya existentes con anterioridad a 1975, es decir, la ampliación de la oferta de plazas en centros públicos sobre todo para niños de cuatro y cinco años de edad. Los decisores políticos en el área de educación han concebido las experiencias de los niños en centros educativos como beneficiosas para ellos, entre otras razones, porque desarrollan su sociabilidad y su potencial para el aprendizaje en el futuro.

Las autoridades educativas han sostenido que las experiencias educativas previas a las obligatorias son especial mente enriquecedoras para los menores que provienen de las familias más desfavorecidas económica, social y culturalmente, hasta el punto de poder compensar, en parte, las diferencias existentes entre estos menores y los que provienen de familias acomodadas (Boyd-Barrett, 1995: 10; M EC, 1989b: 104). Al aumentar la oferta de plazas en centros escolares públicos (gratuitos en la actualidad), han intentado atemperar el desigual acceso de los niños de distinta extracción socioeconómica a estos niveles educativos. En efecto, parece claro que en los años setenta y ochenta, debido, entre otros factores, a la escasa oferta de plazas en centros públicos, y a la preponderancia del sector privado en este ámbito, la educación preescolar, con fre-

24. Para analizar el papel de las autoridades educativas me he basado en las siguientes fuentes: la LO GSE y otros textos legislativos, documentos publicados del M EC, por ejemplo: M EC, 1989a: 103-104, publicaciones escritas por decisores políticos del M EC, por ejemplo: M archesi (1990: 34-35), secretario de Estado de Educación, además de entrevistas realizadas a tres altos funcionarios en dicho M inisterio. 
cuencia, multiplicaba las desigualdades sociales ya existentes. Sucedía así debido a que eran proporcionalmente muchos los niños procedentes de familias con más recursos quienes participaban en experiencias educativas previas a las obligatorias (D e Puelles Benítez, 1986: 448-449; G onzález-Anleo, 1985: 74; M edina, 1976: 123; M uñoz-Repiso I zaguirre y otros, 1992: 21-22).

Es preciso destacar que las fuentes educativas consultadas enfatizan que lo que ofrecen los centros públicos a los menores de seis años son programas educativos, y en absoluto servicios de guardia y custodia de los niños (que podrían favorecer a sus madres en la tarea de compatibilizar sus obligaciones laborales y familiares) ${ }^{25}$. Por ejemplo, en el Libro Blanco para la Reforma del Si stema Educativo, que contiene los principios básicos de la reordenación puesta en práctica posteriormente con la LO GSE, se afirma que «en contraposición con el marcado carácter de guarda y custodia que frecuentemente ha tenido la asistencia de niños en centros extrafamiliares, todo el período previo a la escolarización obligatoria debe tener un inequívoco sentido educativo» (M EC, 1989b: 103). Es más, en algunas fuentes se encuentran implícitas dos suposiciones. En primer lugar, la proposición de que un programa educativo y un servicio de cuidados constituyen medidas antagónicas e irreconciliables, de modo que un centro puede ofrecer uno u otro pero no ambos. En segundo lugar, la afirmación de que quienes trabajan en centros educativos públicos son educadores (para lo que se requiere una formación adquirida en escuelas universitarias o en facultades) y no cuidadores (función para la que se supone que no se necesita ningún tipo de preparación especial).

El énfasis puesto en el carácter educativo de los programas anteriores a la escolarización obligatoria ha inducido a las autoridades ministeriales a realizar en los últimos años, en colaboración con expertos, directores y enseñantes de algunos centros, un notable esfuerzo por dotar estos programas del contenido pedagógico y de los medios de enseñanza apropiados para niños menores de seis años, cometido al que han dedicado recursos y atención (D e Puelles Benítez, 1987: 315; M EC, 1989b: 41). De este modo, han intentado distanciarse de un pasado en el que, según su punto de vista, muchos centros públicos y privados eran en realidad simples lugares de custodia de niños que no

25. Paradójicamente, las referencias a la utilidad que los programas educativos pueden reportar a las madres de los menores de seis años, en el caso de que éstas realicen trabajo extradoméstico, están contenidas en fuentes ministeriales del período franquista, por ejemplo en el llamado «Libro Blanco» de 1969, que comprendía los estudios preparatorios y las directrices básicas de la futura L ey G eneral de Educación de 1970 (M EC, 1969a: 43, 211; 1969b: 12). Es preciso destacar que los decisores políticos del régimen autoritario erigieron en los momentos fundacionales del régimen numerosas barreras a la participación de las mujeres (sobre todo de las casadas) en el mercado de trabajo (por ejemplo, despidos por matrimonio en al gunas empresas públicas), si bien desde finales de los años cincuenta las élites políticas fueron demoliendo paulatinamente la mayor parte de estos obstáculos. Ello no obstante, si bien la extensión del trabajo extradoméstico de las mujeres terminó siendo tolerada por las autoridades franquistas, nunca fue considerada un fenómeno deseable, ni, en general, fue incentivada con políticas públicas (Valiente Fernández, 1994: 155-166). 
podían ser atendidos durante esas horas por sus madres, o bien seudoescuelas primarias, cuyos objetivos y métodos pedagógicos tal vez fuesen los apropiados para niños más mayores, pero en absoluto para los menores de seis años (M EC, 1989b: 89).

Si la asistencia a un centro educativo es definida en el período democrático como una medida de carácter pedagógico diseñada en beneficio de los menores, es de suyo preguntarse por la edad a la que los niños deberían comenzar esta experiencia. Las concepciones pedagógicas del pasado la fijaban en torno a los seis años (D e Puelles Benítez, 1986: 447-448). En la actualidad, no existe un acuerdo absoluto acerca de tal cuestión, pero las autoridades educativas creen que es aproximadamente los tres años, si bien hace dos décadas se pensaba que era un poco más elevada, en torno a los cuatro (I M , 1990a; M edina, 1976: 115). En la práctica, esta idea se ha visto reflejada en el establecimiento de dos políticas bien diferenciadas: una extensa oferta de plazas en centros públicos para niños mayores de tres años, y un número muy reducido de ellas para los más pequeños. D ebe añadirse que importantes sectores de la población están de acuerdo con esta idea acerca de la edad a la que los niños deben comenzar a acudir a centros educativos, como se puso de manifiesto, por ejemplo, en una encuesta representativa de ámbito nacional realizada a mujeres con niños menores de seis años que vivían en ciudades de más de 30.000 habitantes encargada por el Instituto de la M ujer (IM , 1990a: 50-54).

Es necesario estudiar la política educativa dirigida a los niños de hasta seis años en el contexto de la política educativa general. D urante los últimos veinte años cuatro han sido (como mínimo) las cuestiones que las autoridades educativas han considerado prioritarias (y mucho más importantes que la extensión de los programas anteriores a la escolarización obligatoria): un nivel del $100 \%$ en las tasas de escolarización para las edades de seis a trece años (período de escolarización obligatoria hasta 1990), lo que se consiguió a principios de los ochenta (M EC, 1989b: 32); Ia transferencia de competencias en materia educativa a las comunidades autónomas, proceso iniciado en la década de los ochenta; la política de subvenciones a centros privados que ofertan plazas en niveles obligatorios de enseñanza en determinadas condiciones, y, por último, la ampliación de dos años de la etapa educativa obligatoria (14-16 años), obje tivo marcado en la LO GSE. Puede afirmarse que la ampliación de la enseñanza previa a la etapa obligatoria no ha constituido una meta preferente de las autoridades educativas en la década posterior a 1975 (D e Puelles Benítez, 1986: 447; M EC, 1989b: 17; Rivière Gómez y otros, 1988: 65), si bien se le ha concedido más importancia en los últimos diez años ${ }^{26}$.

26. Un indicio de ello es la poca atención prestada a la enseñanza de niños menores de seis años en las publicaciones del M EC. H e consultado los 66 números de la Revista de Educación publicados entre noviembre de 1975 y diciembre de 1995. Cada ejemplar contiene un número variable de artículos, en torno a quince. En los veinte años estudiados, sólo se publicaron deciocho artículos sobre el tema que nos ocupa, no habiéndose dedicado ni un solo número monográfico al mismo. 
Si las cuatro prioridades en materia educativa citadas en el párrafo anterior han desplazado sistemáticamente la extensión de los programas para niños menores de seis años a la categoría de objetivos secundarios, otros factores han facilitado su desarrollo. El más importante de ellos es el descenso de las tasas de natalidad. El menor número de niños ha hecho posible, en primer lugar, que la meta de escolarizar a todos los comprendidos entre seis y trece años se alcanzase con mayor facilidad. D e otro lado, al ser también menos los menores de 6 años, han podido ser admitidos en centros públicos en proporciones más elevadas (C obo Suero, 1994: 1121; Consejo Escolar del Estado, 1993: 108; M EC, 1989b: 40; Rivière Gómez y otros, 1988: 70).

C abe añadir que la extensión de los programas educativos para niños mayores de tres años ha podido incluirse en la agenda política gubernamental debido, en parte, al carácter no controvertido de esta medida. En efecto, el nivel de gasto público en educación durante el régimen de Franco había sido muy bajo hasta, por lo menos, los años setenta. $\mathrm{H}$ a resultado entonces relativamente fácil para las élites políticas argumentar que este reducido gasto educativo había supuesto un retraso histórico de España, que se había traducido en una deficiente preparación educativa de gran parte de la población española, y que tal déficit había de subsanarse con una creciente oferta de puestos escolares, incluso en los niveles no obligatorios. Por otra parte, las instituciones educativas ya estaban en pie, por lo que sólo se trataba de expandirlas. Lo contrario sucedía para el caso de los servicios (no educativos) de cuidados de los niños, que prácticamente no habían sido ofertados por el Estado, por lo que no existían instituciones encargadas deello.

En cuanto a la igualdad de oportunidades entre los individuos de ambos sexos, los decisores políticos en materia educativa han entendido que su aportación en esta cuestión de ninguna manera consistía en ofertar servicios de cuidados a los niños pequeños para que sus madres trabajaran (una vez que terminan las bajas de maternidad) ${ }^{27}$, sino en ofrecer a los alumnos de todos los niveles una educación no-sexista ${ }^{28}$. Para el conjunto del sistema educativo

27. En España, las mujeres que han cotizado a la Seguridad Social al menos 180 días durante los cinco años previos al nacimiento de su hijo, tienen derecho a dieciséis semanas ininterrumpidas de baja por maternidad (dieciocho en caso de parto múltiple). Las mujeres pueden decidir cuándo se acogen a esta medida, con la única condición de que seis semanas sean disfrutadas después del parto. D urante todo el período la madre recibe del Instituto $\mathrm{N}$ acional de la Seguridad Social un subsidio correspondiente al $100 \%$ de la base reguladora. Ésta se calcula utilizando el nivel de cotización a la Seguridad Social (que es proporcional al salario) y el período cotizado. La madretiene derecho al reingreso en el mismo puesto de trabajo. D esde 1989 (Ley 3 de 3 de marzo), si ambos progenitores trabajan, el padre puede tomar hasta cuatro de las últimas semanas de la baja de maternidad, en cuyo caso la madre debe volver al trabajo. El número de hombres que está haciendo uso de este derecho es sumamente reducido: según datos de la Encuesta de Población Activa correspondientes al último trimestre de 1995, el 99\% de los ocupados acogidos al permiso de maternidad eran mujeres y el 1\%, hombres (IN E, 1996: 205).

28. El ordenamiento jurídico en materia educativa contiene numerosas referencias a la igualdad entre las personas de uno y otro sexo. Por ejemplo, la LO GSE hace con frecuencia mención a ella (preámbulo, párrafos 2, 5, 13 y 22; arts. 2.3.c, 13.d, 19.d, 57.3 y 60.2). 
(incluida la educación infantil) ello ha cristalizado, entre otras actuaciones, en intentos de erradicar estereotipos sexistas en el material didáctico y en el curriculum académico, o en conseguir que niños, adolescentes y jóvenes de ambos sexos accedan a todo tipo de opciones educativas. En esta dirección, las autoridades educativas han colaborado inten samente con el Instituto de la M ujer, una de cuyas prioridades desde el momento de su creación ha consistido en impulsar acciones de igualdad en el ámbito de la educación (IM , 1987: 41-52; 1993b: 39-54).

Al concentrar sus esfuerzos y recursos en el desarrollo de programas educativos para niños de cuatro y cinco años y en menor medida de tres, desde 1975 los decisores políticos en materia educativa han supuesto, junto con el resto de la élite política, que, en general y salvo casos muy excepcionales, del cuidado de los niños menores de tres años se encargan, de modo exclusivo, sus familias (esto es, sobre todo sus madres) y no el Estado. Las autoridades gubernamentales han regulado, más tardía y laxamente que en otros países, los servicios ofertados por los centros privados, sabiendo que dichos servicios son cruciales para al gunos de los núcleos familiares en los que una madre ama de casa no está disponible día y noche para encargarse de sus hijos, y no es sustituida en tal menester por un pariente (generalmente femenino) o por una empleada de hogar.

Lo mismo puede afirmarse respecto del sector de cuidados proporcionados en los domicilios a cambio de pagos en dinero. Los decisores políticos dejan enteramente en manos de las familias la responsabilidad de negociar con los cuidadores las condiciones en que éstos se encargan de los niños. N o resulta sencillo explicar por qué ello sucede así en España, donde el grado de intervención del Estado en otros ámbitos, por ejemplo, en el mercado de trabajo, es considerablemente elevado en términos comparativos. Posiblemente sostengan los decisores políticos que las atenciones que reciben quienes necesitan de los cuidados de otras personas (por ejemplo, los niños pequeños, pero no sólo ellos) constituyen una responsabilidad exclusiva de ellas y de sus familiares. Además, y a la vista de lo expuesto más arriba sobre la definición que las autoridades educativas formulan sobre los servicios ofertados en centros educativos públicos (como programas educativos y no meros servicios de guardia y custodia), cabe sospechar que opinan que el trabajo de cuidar a los niños puede ser realizado por cualquiera. Se trataría, pues, de una tarea poco importante, que no necesita (ni merece) reglamentación estatal.

La implantación de una regulación estatal en el sector domiciliario como las que se aplican en otros países significaría (en caso de que la regulación se cumpliera) que muchos de estos cuidadores no podrían continuar prestando sus servicios en las condiciones en que actual mente lo hacen. Algunos perderían una fuente de ingresos que, dado el alto nivel de paro y de subempleo que caracteriza al mercado de trabajo español, no podrían conseguir empleándose en otra ocupación (CECS, 1994: 371). Ello constituiría, además, un problema de considerables dimensiones para las madres, dada la dificultad para muchas de encontrar a corto plazo otras alternativas satisfactorias. Por supuesto, a largo 
plazo esta reglamentación supondría la eliminación del sector de personas que se ocupan de niños en condiciones tal vez perjudiciales para estos últimos, aunque no está claro quién podría, percibiendo los mismos y no más elevados salarios, reemplazarlas en tales cometidos.

D e otro lado, las élites políticas saben que la cultura política de los españoles es estatista, y que la población, en general, cree que el Estado debe intervenir en numerosos ámbitos de la vida económica y social (Beltrán, 1990: 318-319). Conocen entonces los riesgos que conlleva intervenir en el sector de cuidados domiciliarios sin aumentar significativamente la oferta de plazas en centros públicos: cualquier interferencia en el statu quo podría incentivar a los padres a que se dirigieran a las autoridades en busca de soluciones para el cuidado de sus hijos (algo que los decisores políticos en todo momento han deseado evitar).

\section{Conclusión}

En este trabajo he descrito en términos comparativos las principales políticas de cuidado de los niños de ámbito nacional en España después de 1975: una amplia oferta de plazas educativas en centros públicos para niños de cuatro y cinco años (lo contrario es cierto en el caso de los menores de tres); una regulación estatal de las condiciones en que ofertan sus servicios los centros privados más tardía y menos detallada que la de otros países; la ausencia de reglamentación por parte de las autoridades del sector de cuidados domiciliarios, y la introducción de exenciones fiscales para al gunos de los contribuyentes del IRPF que hayan incurrido en gastos en concepto de custodia de sus hijos. La continuidad ha caracterizado este área de actuación pública, ya quela medida más importante antes y después de 1975 ha consistido en la extensión de los programas educativos en centros públicos para niños de cuatro y cinco años.

La literatura teórica sobre el establecimiento de la agenda política resulta útil para analizar las medidas relativas al cuidado de los niños en edad anterior a la de escolarización obligatoria de ámbito nacional en España después de 1975. La necesidad de establecer servicios de cuidados de los niños a fin de facilitar que sus madres compatibilicen sus responsabilidades familiares y laborales no se ha incluido en la agenda gubernamental, en parte porque esta cuestión no ha contado con «val edores». Los estudios teóricos afirman que es poco probable que un asunto sea introducido en la agenda, si su solución cuenta con poca viabilidad económica, no es acorde con la capacidad institucional del Estado para interferir en la cuestión y si amplios sectores de la población opinan que el Estado ha de mantenerse al margen. Estas proposiciones se confirman en el caso que nos ocupa, ya que en las últimas dos décadas no ha existido escasez sino exceso de oferta de trabajadores en el mercado laboral. Por otra parte, el Estado de bienestar en España (con las excepciones de la sanidad y la educación) ofrece principalmente transferencias para mantener un cierto nivel de renta para determinados individuos, pero no servicios sociales personales 
(entre ellos los de cuidados). Además, son muchos quienes creen que los cuidados maternos dispensados en el hogar constituyen la mejor forma de criar a los niños pequeños.

Esta investigación revela la importancia, en determinados casos, de un factor poco tenido en cuenta por la literatura teórica: la existencia de un pasado político autoritario, que desincentive la aparición de «promotores» de una política pública. Así, las militantes en el movimiento de mujeres y las feministas de Estado han evitado representar el papel de «valedoras» de una política de igualdad de género relativa a los servicios de cuidado de los niños, en parte por influencia indirecta del período franquista. D ebido a la duración del mismo, en 1975 el número de tareas pendientes en materia de igualdad entre hombres y mujeres era muy elevado, por lo que tuvieron que dejar de lado algunas de ellas. Además, no prestaron demasiada atención a la maternidad y a cuestiones con ella relacionadas (el cuidado de los hijos, por ejemplo), en un intento de rechazar el discurso oficial franquista, el cual mantuvo insistentemente que la maternidad constituía la principal obligación de las mujeres para con el Estado y la sociedad.

N uestro caso de estudio confirma la hipótesis de que el modo de definir un problema condiciona la solución propuesta para resolverlo. Los decisores políticos en materia educativa han actuado en este ámbito como los «promotores» de un problema, a saber, de la escasez de oferta de plazas en centros educativos públicos para niños menores de seis años. $H$ an apoyado también una solución: el aumento de dicha oferta. Así, han extendido los programas educativos que ya existían antes de 1975 para niños pequeños. Esta línea de actuación constituía uno de los compromisos programáticos en materia educativa de los partidos políticos que han formado el Gobierno o han constituido la principal fuerza de la oposición: U CD, el PSO E y el PP.

El problema de la falta de oportunidades educativas para un alto número de menores de seis años ha formado parte de la agenda política gubernamental (si bien ha ocupado en ella una posición menos importante que otras cuestiones educativas), en parte debido a su carácter no controvertido. D ado el bajo gasto público en educación, resultaba relativamente fácil argumentar que este retraso histórico debía ser superado. D e otro lado, el Estado ya ofertaba plazas preescolares antes de 1975. Ello significaba que al gunos centros ya estaban en pie, que al gunos maestros ya proporcionaban enseñanza a niños sobre todo de cuatro y cinco años, y que en el M EC algún departamento 0 sección se encargaba de coordinar o dirigir estos programas educativos. En otras palabras, la infraestructura ya estaba creada, y sólo era necesario expandirla. Por el contrario, el Estado prácticamente no había ofrecido servicios no educativos de cuidado de niños; caso de desear empezar a hacerlo, los decisores políticos habrían de haber comenzado por poner en pie una burocracia adecuada.

En lo que concierne a años venideros, es previsible que la demanda de servicios de cuidado de niños aumente en el futuro por varias razones, entre ellas la creciente participación de la mujer en el mercado laboral (D oz O rrit, 1995: 
84). Anteriormente he afirmado que las tasas de actividad y ocupación femeninas son muy bajas en términos comparativos. Ello no obstante, según puede apreciarse en la tabla 3, su valor no es tan reducido en lo que concierne a las mujeres menores de 40-45 años, entre las que se encuentran las madres de niños en edad anterior a la escolarización obligatoria. Es más, dichas generaciones de mujeres intentan no dejar de trabajar tras el matrimonio o el nacimiento de sus hijos, lo que no sucedía en el pasado (CES, 1994: 11). Por otra parte, en todos los países occidentales existen factores que incrementarán la demanda de servicios de cuidado de niños: el deseo de un número creciente de progenitores de que sus hijos participen en actividades junto con otros niños, para que aumente su sociabilidad y su capacidad de aprendizaje futuro, así como la aspiración por parte de al gunos padres de poder contar con algo de tiempo para sí mismos (Ergas, 1990: 211; O CDE, 1990: 298-302). Así las cosas, la cuestión acerca de la organización del cuidado de los niños formará parte de los problemas que concernirán de modo individual a muchos adultos. Sin embargo, no es previsible que las actuaciones de los actores estudiados en este trabajo vayan a modificarse a corto plazo, por lo que resulta difícil imaginar cambios significativos en las políticas relativas al cuidado de niños pequeños en los próximos años.

$V$ isto en retrospectiva, podría parecer que el desarrollo de los programas educativos para niños de tres a seis años ha venido desplazando, y desplazará,

Tabla 3. Tasass de actividad, ocupación y paro (\%) femenino por edades, España, cuarto trimestre de 1995.

\begin{tabular}{llll}
\hline Edad & Actividad & Ocupación & Paro \\
\hline $16-19$ & 22 & 9 & 56 \\
$20-24$ & 58 & 31 & 47 \\
$25-29$ & 73 & 46 & 37 \\
$30-34$ & 63 & 44 & 30 \\
$35-39$ & 60 & 45 & 26 \\
$40-44$ & 54 & 42 & 23 \\
$45-49$ & 45 & 36 & 18 \\
$50-54$ & 35 & 29 & 17 \\
$55-59$ & 26 & 22 & 13 \\
$60-64$ & 15 & 14 & 9 \\
$65-69$ & 3 & 3 & 2 \\
$70-$ & 1 & 1 & 3 \\
Total & 36 & 25 & 30 \\
\hline
\end{tabular}

Fuente: cálculos propios a partir de datos contenidos en INE (Instituto N acional de Estadística) 1995. Encuesta de Población Activa: resultados detallados, cuarto trimestre de 1995. M adrid: INE, 1996, p. 44, 152, 234. 
al establecimiento de otras medidas relacionadas con el cuidado de los menores. Los decisores políticos siempre podrán argumentar que ya se han dedicado notables recursos y realizado notorios esfuerzos para incrementar las oportunidades educativas de estos menores (una cuestión de responsabilidad pública), por lo que las familias habrán de continuar cumpliendo con lo que muchas personas consideran que son sus obligaciones, por ejemplo, cuidar de los menores (una responsabilidad privada). D e este modo, la consolidación de una determinada política pública, puede constituir una barrera para la puesta en marcha de otras medidas dentro del mismo ámbito de actuación pública, fenómeno no predicho por la literatura sobre el establecimiento de la agenda.

A partir de las conclusiones de este artículo pueden esbozarse futuras líneas de investigación. En primer lugar, respecto a las medidas relativas al cuidado de los niños, pueden apreciarse continuidades sustantivas entre el régimen autoritario y el democrático. Cabría preguntarse si en otros ámbitos existen tales continuidades 0 , por el contrario, se han producido rupturas, y qué factores ayudan a explicar su aparición. En segundo lugar, las políticas de cuidado de los niños en España son en la actualidad las formuladas por el M EC y por las CCAA con competencias plenas en educación. Un estudio como éste, dedicado a las primeras medidas, ha de ser necesariamente completado con la investigación sobre las actuaciones de las autoridades regionales en esta materia, que pueden diferir en cierta medida de las elaboradas por el M EC, por ejemplo, en cuanto a la financiación a centros privados.

Por último, según el análisis del papel de los decisores políticos en materia educativa en el caso que nos ocupa, éstos han enfatizado que los programas ofertados por centros públicos a niños menores de seis años son de carácter educativo y no un «mero» servicio de cuidados. $\mathrm{H}$ an entendido que las actividades educativas (no las de cuidados) consisten en estimular en los niños determinadas habilidades y capacidades que les permitan aprender más y mejor en el futuro, además de proporcionarles ciertos conocimientos. También han dejado entrever su opinión de que la organización de experiencias educativas es un cometido importante, que tiene lugar preferentemente en centros, y que requiere de personal formado en el sistema universitario, mientras que las tareas de cuidados se llevan a cabo casi siempre en el hogar y pueden ser realizadas adecuadamente por cualquier persona, sin ninguna preparación especial. Resulta obvio que esta definición de ambos menesteres prestigia la importancia del primero. Sería interesante analizar si, en otras áreas de actuación pública (por ejemplo la sanitaria), también se produce este desprestigio velado por el trabajo de cuidar a las personas, en beneficio de otras actividades consideradas más «técnicas» y «profesionales», como combatir desde el punto de vista clínico la enfermedad que las inhabilita, averiguar si esto es, hasta cierto punto, privativo de España y, si así fuera, qué factores pueden dar cuenta de las diferencias de rango de que gozan las tareas mencionadas. 


\section{Bibliografía}

Aguin aga Roustán , Josune; Com As Arn Au, D omingo (1991). Infancia y adolescencia: la mirada de los adultos. M adrid: M inisterio de Asuntos Sociales.

AlberdI, Inés; Flaquer, Lluís; I gLeSIAS DE U SSEL, Julio (1994). Parejas y matrimonios: actitudes, comportamientos y experiencias. M adrid: M inisterio de Asuntos Sociales.

BACH RACH, Peter; BARATZ, M orton S. (1962). «Two Faces of Power». American Political Science Review. Vol. 56 (diciembre): 947-952.

BELTRÁN, M iguel (1990). «La administración pública y los funcionarios». En España: sociedad y política. Ed. por Salvador Giner, p. 315-352. M adrid: Espasa-C al pe.

Berm EO, N ancy (1992). «D emocracy and the Lessons of D ictatorship». Comparative Politics (abril): 273-291.

BoRCH ORST, Anette (1990). «Political Motherhood and Child Care Policies: a Comparative Approach to Britain and Scandinavia». En Gender and Caring: Work and Welfare in Britain and Scandinavia. Ed. por Clare Ungerson, p. 160-178. $N$ ueva York y Londres: $\mathrm{H}$ arvester W heatsheaf.

Boyd-BARRETt, O livier (1995). «Structural Change and Curriculum Reform in D emocratic Spain». En Education Reform in Democratic Spain. Ed. por Olivier Boyd-Barrett y Pamela 0 'M alley, p. 6-24. Londres: Routledge.

Bran nen, Julia; O 'Brien, M argaret (eds.) (1995). Childhood and Parenthood: Proceedings of ISA Committee for Family Research Conference on Children and Families, 1994. Londres: Institute of Education, University of London.

Bustelo, Carlota (1980). «M ujer y Socialismo: para cambiar la vida» (folleto).

CCO 0 (Comisiones 0 breras) $(1984,1988,1991)$. 3-5 Congresos federales, resoluciones.

- (1993a). Primera conferencia CCOO sindicato de hombres y mujeres documentos aprobados. M adrid: Secretaría Confederal de la M ujer.

- (1993b). Séptimas jornadas: Las secretarías de la mujer: consolidar, crecer, avanzar. $M$ adrid: Secretaría Confederal de la M ujer.

CECS (Centro de Estudios del Cambio Social) (1994). España 1993: una interpretación de su realidad social. M adrid: Fundación Encuentro.

CES (Consejo Económico y Social) (1994). La situación de la mujer en la realidad sociolaboral española. M adrid: CES.

Co BB, Roger W.; Elder, Charles (1972). Participation in American Politics: The D ynamics of Agenda-Building. Boston: Allyn and Bacon.

C о вo Suero, Juan M anuel (ed.) (1994). «Educación». En V Informe sociológico sobre la situación social en España: sociedad para todos en el año 2000. Ed. por M iguel Juárez, p. 1107-1276. M adrid: Fundación Foessa.

Consejo Escolar DEL EsTAD o (1993). Informesobre el estado y situación del sistema educativo, curso 1991-92. M adrid: Consejo Escolar del Estado.

- (1995). Informe sobre el estado y situación del sistema educativo, curso 1993-94. $M$ adrid: Consejo Escolar del Estado.

Crenson, M atthew A. (1971). The Un-Politics of Air Pollution: A Study of N on$D$ ecisionmaking in the Cities. Baltimore y Londres: The Johns $\mathrm{H}$ opkins Press.

D AUne-RICH ARD, Anne-M arie; M AH ON, Rianne (1996). "“O nly a Parenthesis?": Swedish Family Policy in C risis». Trabajo presentado en la Xth Conference of Europeanists, Chicago, 14-16 marzo. 
De M Iguel, Amando (ed.) (1994). La sociedad española, 1994-1995. M adrid: Complutense.

D e PABLO M ASA, Antonio (1976). «La familia española en cambio». En Estudios sociológi cos sobre la situación social de España. Ed. por Fundación Foessa, p. 345-405. $M$ adrid: Euramérica.

De Puelles Benítez, M anuel (1986). Educación e ideología en la España contemporánea. Barcelona: Labor.

- (1987). Política y Administraciones educativas. M adrid: Universidad N acional de Educación a D istancia.

D ERY, D avid (1984). Problem D efinition in Policy Analysis Lawrence (Kansas): University Press of Kansas.

D oz O RRIT, Javier (1995). «Problems of Implementation in Spanish Educational Reform». En Education Reform in D emocratic Spain. Ed. por O livier Boyd-Barrett y Pamela $O$ 'M alley, p. 79-93. Londres: Routledge.

El País, 4 de agosto de 1996; 8 de octubre de 1996.

ERGAS, Yasmine (1990). «ntroduction à une étude comparée des politiques en matière de garde des enfants». En Les familles monoparentales: les enjeux économiques. París: OCDE.

Escario, Pilar; Alberdi, Inés; Berlín, Belén (1987). Actitudes de los varones ante el cambio familiar: informe de investigación (trabajo no publicado).

EsPIn G-And DeRSEN, Gosta (1990). The Three Worlds of Welfare Capitalism. Princeton ( $N$ ew Jersey): Princeton U niversity Press.

- (1995). «Welfare State without Work: the Impasse of Labor Shedding and Familialism in Continental European Social Policy». Centro de Estudios Avanzados en Ciencias Sociales, Instituto Juan M arch de Estudios e Investigaciones Estudio/Working Paper, núm. 71.

EuRostat (1996). Statistiques en bref: population et conditions sociales, núm. 3.

Fern Án dez SAnZ, M atilde (1990). La política del M inisterio de Asuntos Sociales: comparecencia de la M inistra D a M atilde Fernández Sanz ante la Comisión de Política Social y Empleo del Congreso de los D iputados al inicio de la IV legislatura. M adrid: M inisterio de Asuntos Sociales.

Franzway, Suzanne; Court, Dianne; C on nelL, R.W. (1989). Staking a Claim: Feminism, Bureaucracy and the State. C ambridge: Polity Press.

GeRSON, Kathleen (1988 [1987]). «W hat D o Women Want from M en? M en's Influence on Women's Work and Family Choices». En Changing M en: N ew Directions in Research on M en and M asculinity. Ed. por M ichael S. Kimmel, p. 115-130. N ewbury Park (California): Sage, $2^{\mathrm{a}} \mathrm{ed}$.

G on ZÁLEZ-AN LEO, Juan (1985). El sistema educativo español. M adrid: Instituto de Estudios Económicos.

GuILlÉN, Ana M . (1992). «Social Policy in Spain: From Dictatorship to D emocracy (1939-1982)». En Social Policy in a Changing Europe. Ed. por Zuzsa Ferge y Jon E. Kolberg, p. 119-142. Frankfurt am M ain y Boulder (C olorado): C ampus Verlag y Westview Press.

- (1996). «C itizenship and Social Policy in D emocratic Spain: the Reformulation of the Francoist W elfare State». South European Society and Politics, núm. 2 (en prensa).

G U STAFSSO N, Siv (1994). «Childcare and Types of Welfare States». En Gendering Welfare States. Ed. por Diane Sainsbury, p. 45-61. Londres: Sage. 
I GLESIAS DE U SSEL, Julio (1984). «La relación infancia y familia en España». Revista Española de Investigaciones Sociológicas, núm. 27 (julio-septiembre): 7-39.

In STITUTO DE LA M UJER (1986). El Instituto de la M ujer 1983-1986. M adrid: Instituto de la Mujer.

- (1987). I Plan para la I gualdad de O portunidades delas M ujeres, 1988-1990. M adrid: Instituto de la M ujer.

- (1988, 1989, 1990b, 1991, 1992, 1993a, 1994). M emoria de actividades. M adrid: Instituto de la M ujer.

- (1990a). El reparto de responsabilidades familiares análisis de la demanda femenina y sus expectativas sobre las redes de cuidados de hijos. M adrid: Instituto de la M ujer.

- (1993b). II Plan para la I gualdad de 0 portunidades de las M ujeres, 1993-1995. $M$ adrid: Instituto de la M ujer.

IN STITUTO N ACIONAL DE ESTAD ÍSTICA (1977). Estadística de la enseñanza en España: curso 1975-76. M adrid: INE.

- (1981). Censo de población, tomo I, volumen I, resultados nacionales, características dela población. M adrid: INE.

- (1994). Censos de Población y Viviendas 1991, características generales dela población, tomo I, resultados nacionales. M adrid: IN E.

- (1995). M ovimiento natural de la población española 1992, tomo I, resultadosa nivel nacional y su distribución por provincias y capitales. M adrid: IN E.

- (1996). Encuesta de Población Activa, resultados detallados, cuarto trimestre de 1995. M adrid: IN E.

IN N ER (1988). Los hombres españoles. M adrid: Instituto de la M ujer.

Jen SON, Jane; SIn EAU, M ariette (1996). «"Au Foyer Citoyennes!" Gender Relations and Changing $C$ hildcare Policy in Frances. Trabajo presentado en la Xth Conference of Europeanists. Chicago, 14-16 de marzo.

Juste Ortega, M aría G.; Ram írez M ayoral, Ana; Barbadillo Griñ án, Patricia (1991). Actitudes y opiniones de los españoles antela infancia. M adrid: Centro de Investigaciones Sociológicas.

Kah N, Alfred J.; Kam erm AN, Sheila B. (1987). Child Care: Facing the H ard Choices. Westport (Connecticut): Auburn H ouse.

KIN GD OM, John W. (1984). Agendas, Alternatives, and Public Policies Glenview (Illinois) y Londres: Scott, Forest and Company.

LeIRA, Arnlaug (1990). «C oping with C are: M others in a Welfare State». En Gender and Caring: Work and Welfare in Britain and Scandinavia. Ed. por Clare Ungerson, p. 133-159. N ueva York y Londres: $\mathrm{H}$ arvester W heatsheaf.

M ARCH ESI, Álvaro (1990). «La educación infantil». Infancia y Sociedad, núm. 1: 33-40. M ARSIG LIO, W illiam (1995). «Fatherhood Scholarship: An O verview and Agenda for the Future». En Fatherhood: C ontemporary Theory, Research, and Social Policy. Ed. por W illiam M arsiglio, p. 1-20. Thousand $O$ aks (C alifornia): Sage.

M CN AIR, John M . (1984). Education for a Changing Spain. M anchester: M anchester University Press.

M INISTERIO DE EdUCACIÓN Y Ciencia (1969a). La educación en España: bases para una política educativa. Vol. I. M adrid: M EC.

- (1969b). La educación en España: bases para una política educativa. Vol. II, Informes. M adrid: MEC.

- (1989a, 1991, 1992, 1993, 1994a, 1994b, 1995). Estadística de la enseñanza en España: educación infantil/preescolar, general básca/primaria y enseñanzas medias/ense ñanza secundaria. M adrid: MEC. 
- (1989b). Libro Blanco para la reforma del sistema educativo. M adrid: M EC.

M EDIN A, Aurora (1976). «Problemática de la educación preescolar en España». Revista de Educación, núm. 247 (noviembre-diciembre): 111-134.

M INISTERIO DE ECONOMía y H ACIENda (1995). M emoria de la Administración Tributaria 1994. M adrid: M EH .

M oss, Peter (1990). «La atención a la infancia en las Comunidades Europeas (19851990)». Cuadernos de M ujeres de Europa, núm. 31.

M UÑ OZ-REPISO IZAGUIRRE, M ercedes y otros (1992). Las desigualdades en la educación en España. M adrid: M EC.

N ASH , M ary (1991). «Pronatalism and M othehood in Franco's Spain». En M aternity and the Rise of the European Welfare States, 1880s-1950s. Ed. por Gisela Bock y Pat Thane, p. 160-177. Londres: Routledge.

N ELSON, Barbara (1984). M aking and I ssue of Child Abuse: Political Agenda Setting for Social Problems. Chicago y Londres: The U niversity of Chicago Press.

O CDE (O rganización para la Cooperación y el D esarrollo Económico) (1990). Perspectivas del empleo, 1990. M adrid: M inisterio de Trabajo y Seguridad Social.

Pérez-D íaZ, Víctor; Ro d Ríguez, Juan Carlos (1994). « ntertial Choices: Spanish H uman Resources Policies and Practices (1959-1993)». Analistas Socio-Políticos Research Paper 2(b).

PP (Partido Popular) (1977, 1979, 1982, 1986, 1993, 1996). Elecciones generales, programas electorales.

PSO E (Partido Socialista O brero Español) (1976, 1979a, 1981, 1984, 1988, 1990,1994). p. 27-33. Congresos federales, resoluciones.

- $(1977,1979 b, 1982,1986,1989,1993,1996)$. Elecciones generales, programas electorales.

- (1980). «iPor qué queremos guarderías?». M ujer y Socialismo (folleto).

- (1977). «C onclusiones de las Jornadas de Estudio "M ujer y Socialismo"». Secretaría de Formación (folleto).

Revista de Educación. N úm. 241 (noviembre-diciembre de 1975). N úm. 308 (septiembre diciembre de 1995).

Rıvière Gó m EZ, Ángel y otros (1988). El sistema educativo español. M adrid: M EC.

RU GGIE, M ary (1984). The State and Working Women: A Comparative Study of Britain and Sweden. Princeton: Princeton University Press.

SCAN LON, Geraldine (1990). «EI movimiento feminista en España, 1900-1985: logros y dificultades». En Participación Política de las M ujeres. Ed. por Judith Astelarra, p. 83-100. M adrid: Centro de Investigaciones Sociológicas y Siglo XXI.

SCH AT TSCH NeIDER, E.E. (1975 [1960]). The Semi sovereign People: a Realist's View of $D$ emocracy in America. H indsdale (Illinois): The D ryden Press.

STETSO N, D orothy M cB ride (1987). Women's Rights in France. N ueva York, Westport (Connecticut) y L ondres: Greenwood Press.

Stetso N, D orothy M cBride; M AzUR, Amy G. (eds.) (1995). Comparative State Feminism. Thousand $O$ aks (California): Sage.

Th ReLfalL, M onica (1985). «T he Women's M ovement in Spain». N ew Left Review N úm. 151: 44-73.

To Bío, C onstanza (1996). Estrategias de compatibilización familia-empleo: España, años noventa (trabajo no publicado).

U CD (Unión de Centro D emocrático) $(1977,1979)$. «Elecciones generales, programas electorales». 
U GT (Unión General de Trabajadores) (1986, 1990, 1994). «34-36 congresos confederales, resoluciones».

Valiente Fern Án dez, Celia (1994). Políticas públicas para la mujer trabajadora en Italia y España (1900-1991). M adrid: Centro de Estudios Avanzados en Ciencias Sociales, Instituto Juan $\mathrm{M}$ arch de Estudios e Investigaciones.

- (1996). «El feminismo institucional en España: el Instituto de la M ujer, 19831994». Revista Internacional de Sociología. N úm. 13 (enero-abril): 163-204.

W ARN ER, Judy (1994). «C hildminders and Children». En Working Together for Young Children: M ulti-profesionalism in Action. Ed. por Tricia D avid, p. 26-34. Londres: Routledge.

W HITTIN GHAM , Vivienne (1994). «C hildminders and Children». En Working Together for Young Children: M ulti-profesionalism in Action. Ed. por Tricia D avid, p. 66-77. Londres: Routledge. 